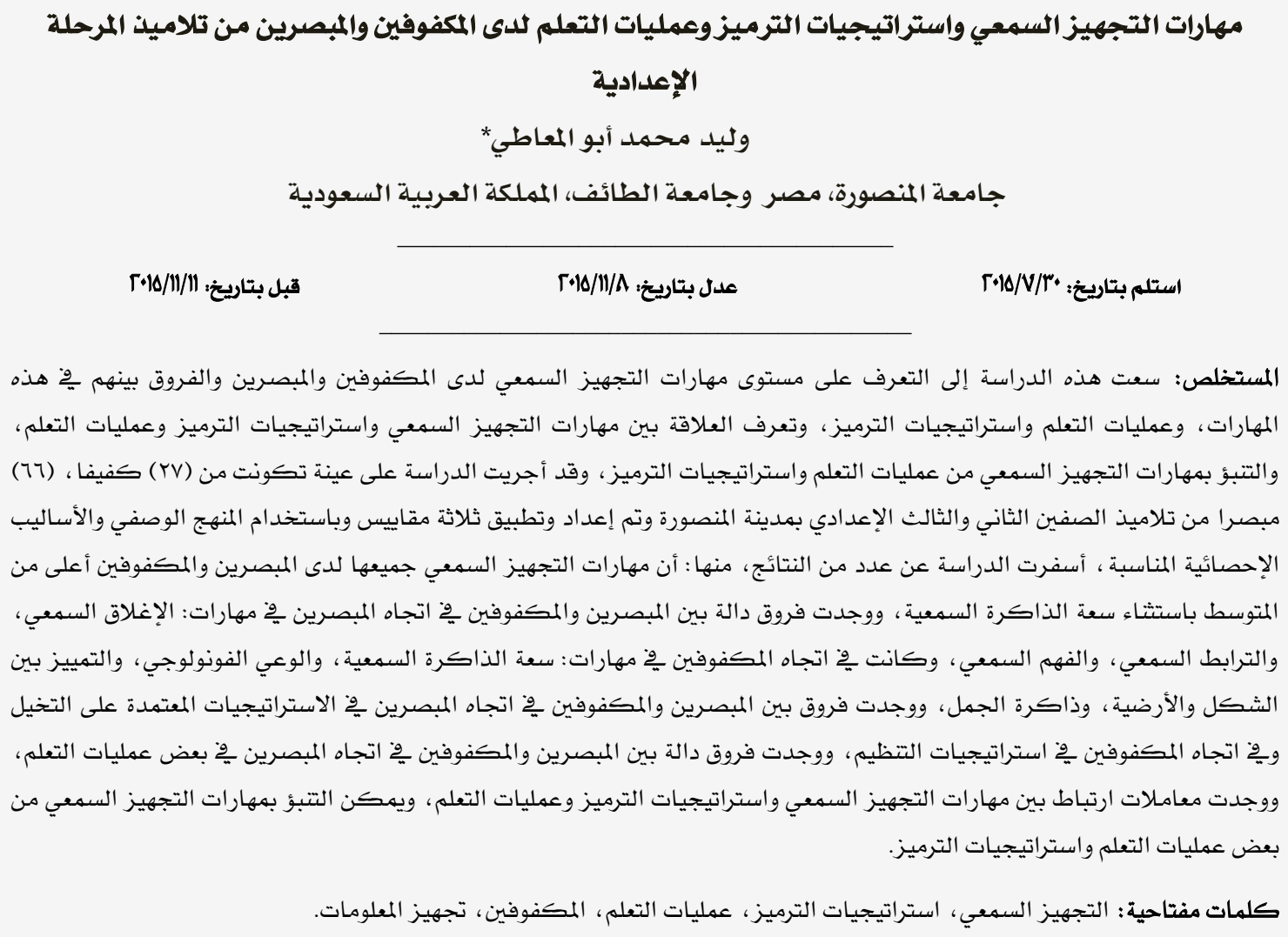

\title{
Auditory Processing Skills, Coding Strategies and Learning Processes of the Preparatory School Blind and the Sighted Students
}

\author{
Waleed M. Abo Elmeaty* \\ Mansoura University, Egypt \& Taif University, Kingdom of Saudi Arabia
}

\begin{abstract}
The present study aims to identify the level of auditory processing skills for the blind and sighted, the differences between them in learning processes, strategies coding and determine the relationship between the auditory processing skills, coding strategies and learning processes. The study was applied on 27 blind, 66 sighted out of second and third Preparatory School student in Mansoura city. Three measures used, descriptive and statistical methods were applied. The results showed that, all auditory processing skills for blind and sighted were above the level. Except the auditory memory capacity, there were significant differences between blind and sighted in direction to sight in skills of auditory: closure, interrelation and comprehension. As well as directed to blind in skills of auditory memory capacity, phonological awareness, distinctive between shape and ground and sentence memory. There was significant differences between sighted and the blind in the direction to sighted in strategies based on imagination, while to blind in organization. There were significant differences between sighted and blind in direction to sight in some learning processes. Positive correlation between the auditory processing skills, learning processes and coding strategies was obrained.
\end{abstract}

Keywords: Auditory processing, coding strategies, learning processes, blind, information processing.

\section{*w2004@mans.edu.eg}


معنى ذلك أن المكفوفين وإن كانوا يعتهمدون

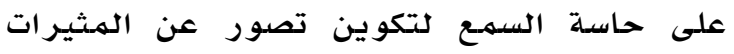

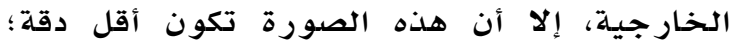

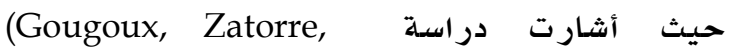
(Lassonde, Voss \& Lepore, 2005 يؤدي دورا حاسهما في تطور بعض التمثيلات السمعية المكانية و تشكيلها، علاوة على ذلك، فإنهان آليات التعويض مثل: الاستثارة العالية، و التناغم المكاني، والتركيب العصبي السمعي يمكن أن الن النيان

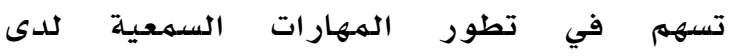
المكفو فين.

وقد سادت لفترة من الزمن فكرة تعويض الحواس، على اعتبار أن الحواس التي تفقد يتم

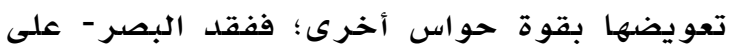
سبيل المثثال- يتمم تعويضه بقوة حاسـة السهمع، و كان للاعتقاد بتفوق المكفوفين في مهارات التجهيز السهعي دافعا للاستعانة بهم لتحليل

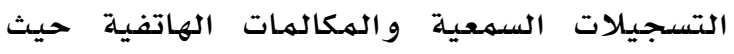

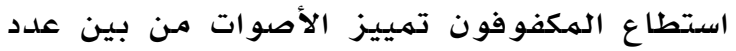
كبير من الأصوات المهتلطة، وأظهر الهكفوفون قدرة كبيرة على الاستدلال وتمييز اللهجات .(Hotting, Roder, 2009, 165)

وظل هذا الاعتقاد سائدا حتى أثبتت معظم

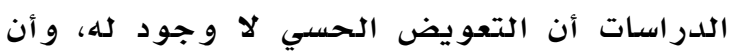
الزيادة الملحوظة في حدة الحواس لدى الكفيف الكيال ترجع إلى استخدامـه لحواسه بطريقة أفضل من

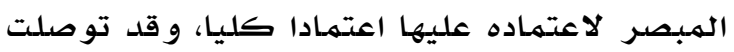
دراسـة (Stevens \& Weaver, 2009) إلى و جودهد انخفاض في الدورة الدموية للاستجابات السمعية

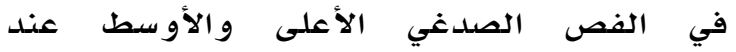
الأشخاص المكفو فين في وقت مبكر ، بالمقارنة

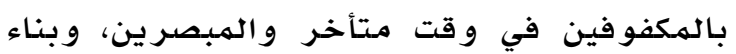
على ذلك فقد توصل إلى استنتاج مؤداه: أن عمليات القشرة السهعية التي تتم على المثيرات

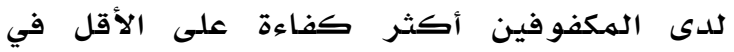

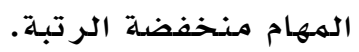

(Vaghefi, Tehrani, Shirazi, كما قارنت در اسـة Rezaei \& Rahgozar, 2013) و المكفوفين في مهارات التجهيز الفونولوجي،

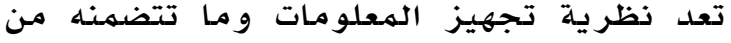
مفاهيم من أكثر المهالات استقطابا لاهتمام

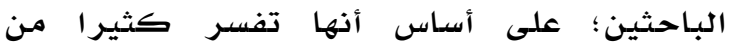
التباين بين الأفراد في عمليات التذكر والتعلدم التهات

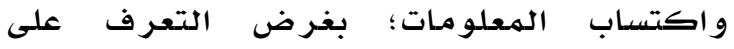
العمليات التي تقف خلف النشاط العقلي للتحكم فيها ور فع كفاءتها.

وتبدأ عملية تجهيز المعلومات بالمدخلات

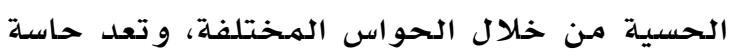

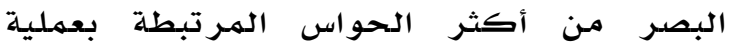

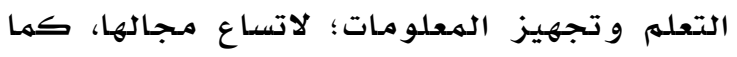
أنها تعطي أنهاطا مختلفة من الشكل و اللون، و تساعد في إدراك العمق و المسافة، ومـن خلالها لها

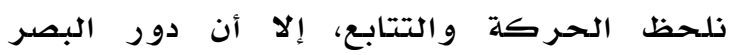

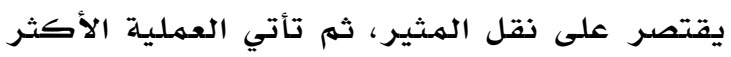

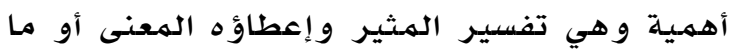
يسمى بالإدر الك البصرئ وهي.

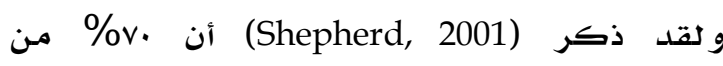
إجمالي سعة الهمخ المخصصدة لتجهيز الهعلومات

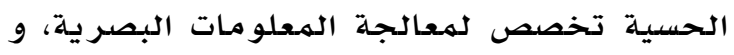

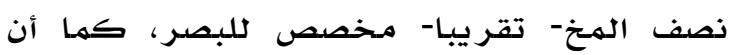
الدراسات التي تناولت الإدراك البصري أفادت

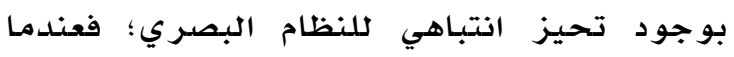

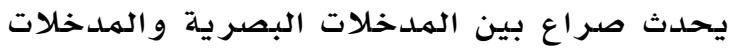

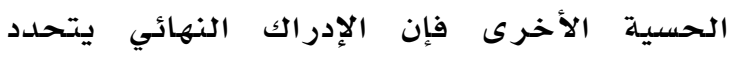

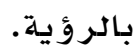
وبناء على ذلك فإن فقد البصر يؤثر سلبا على

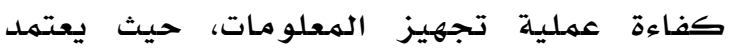
المكفوفون بلدرجة كبيرة على المعلومات التي

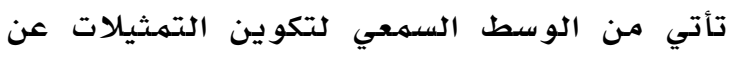
العالم الخارجي؛ فهم مفتقدون لـلإدر الك البصري.

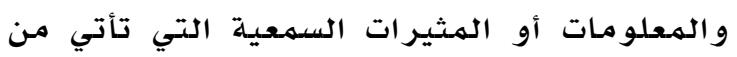

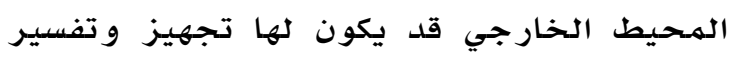
مختلف عما هو لدى المبصرين، فعلى سبيل

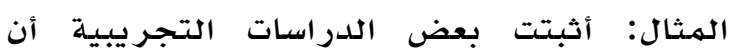
المكفوفين يطورون قدرات فائقة في تجهيز

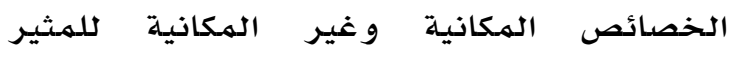
السمعي (Chen, Zhang \& Zhou, 2006, 1449) 
وقد حدد شميك (Schmeck, 1983) أربع عمليات تعلهم هي: العمليات العميقة (Deep processing) و فيها يتميز الطالب بالتقييم النقدي ورتنظيم الهفاهيه، ودراسـة التشابه و التباين في الهعلو مـات بهدف معرفة الفروق بينها، و وعمليات حفظ

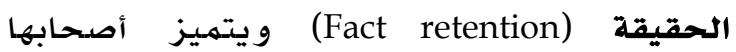
بالدافعية العميقة للتحصيل؛ لذلك يحصلون

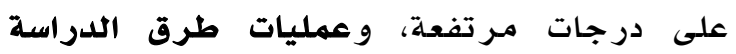

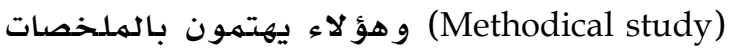

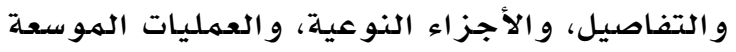
(Elaborate processes)

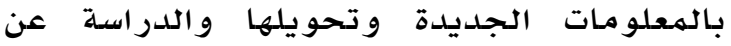

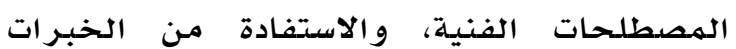

السابقة.

ووفقا للطريقة التي يستخدمها الطالب في تهاب التعلهم تكون قدرته على التذكر والاحتفاظ

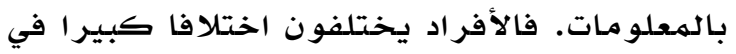

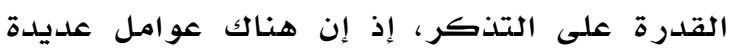
تؤثر في التذكر، مثل: الذكاء، وسعة تجهيز

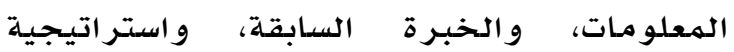
التر ميز المستخدمة. و تعد استر اتيجيات الترميز

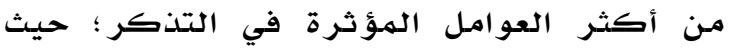
تبين أن الأفراد الذين يستخدمون استراتئجيات و اضحة ومنظمة للتذكر تكون ذاكر تهم أفضل

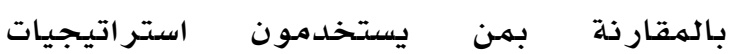

سطحية.. Kirchhoff \& Buckner, 2006, 263). ويتذكر الأفراد بطريقة أفضل إذا تم معالجة

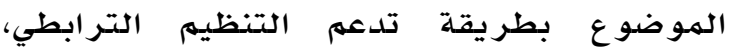

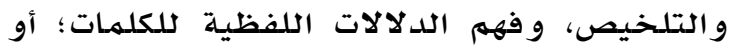

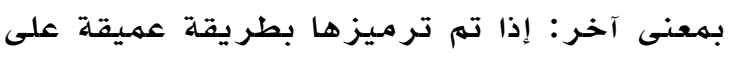

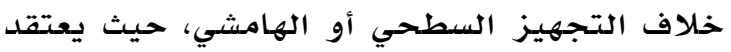

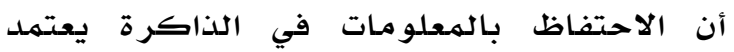
بدرجة كبيرة على قدرة المتعلهم على تطوير

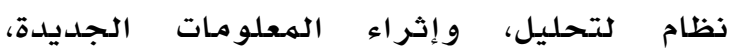

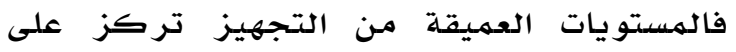
استخلاص المعاني والتحليل المـجرد ذي المعنى فيؤدي إلى حدوث آثار أكثر قوة في الذاكرة الكانيل

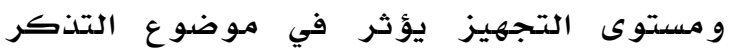
سواء أكان كلمات أو صورا أو موضوعير عاد مـاديا،

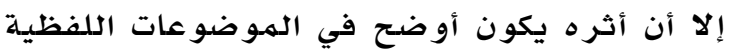

و بلغت العينـة (؟) طفلا من المبصرين و (Y) من المكفوفين، وباستخدام اختبارات اضطر ابات

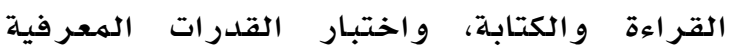

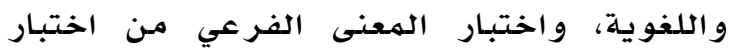

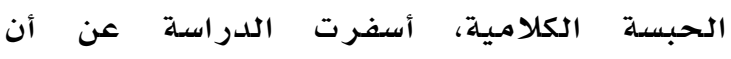
الهبصرين كان أداؤهم أفضل في اختبار التهمييز

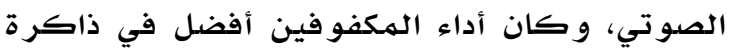

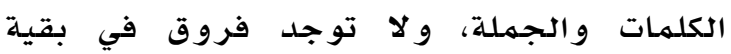
الأبعِاد.

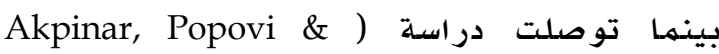

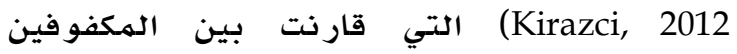

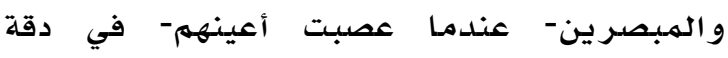
استدعاء مهام الذاكرة المكانية، فلهم توجد فروق بينهما إلا في بعض الاختبارات الفرعية، كمها

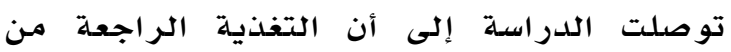
الممكن أن تحسن من دقة أداء المكفو فين. ووفقا لنظرية تجهيز الهعلومات فإنه عندما يتعامل الطلبة مـع كميات كبيرة من المعلومات مـات أكثر من قدرة نظام التجهيز على التعامل معها

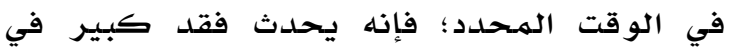

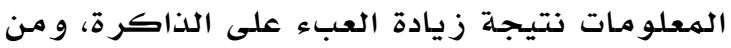

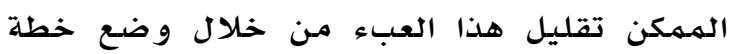
لكيفية تنظيهم وقتهم بين مواد الدراسـ، كما

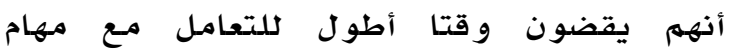
روتينية أكثر من التعامل مـع الهمهام الصعبـة

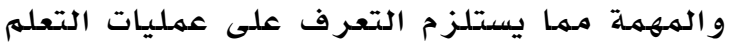

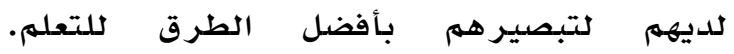
(Benjamin, 2008, 7)

و بناء على ذلك فإن فهم عمليات التعلهم يعد على

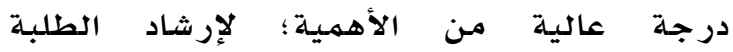
و توجيههم إلى الطرق الفعالة في التعلم والتي ماتهيه تقلل من العبء على عمليات الذاكرة. و وعمليات التعلمم هي الأنشطة المعرفية التي يقوم بهاء التها

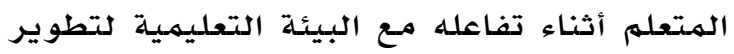

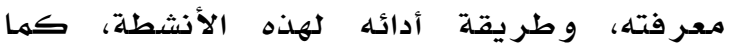

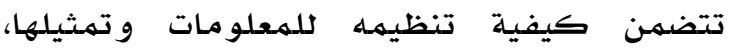
وطريقة تفسيره لها.) ( Phillips, Mc Naught

(Kennedy, 2010 


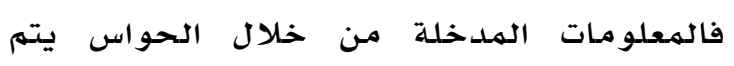

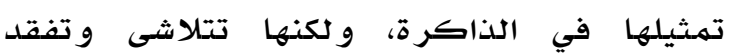

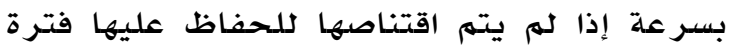

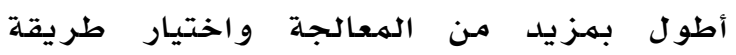

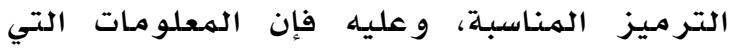

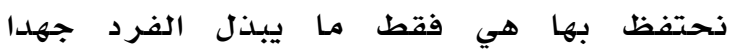

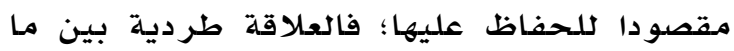
نتذكره ومقدار التناول الإدراكي لله. و ترميز المعلومات نوعان: ترميز للهمعني وفيه

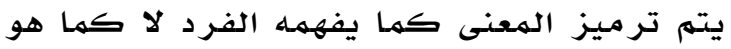

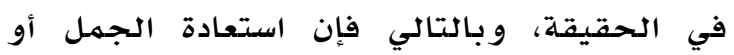

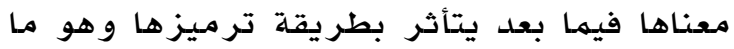
يستخدمه المكفوفون في الغالب، فهم يقرؤون باللمس أو يقرأ لهم آخرون، وهو ما يتطلب نقل المعلومات بشكل يمكنههم من ترميزها وتخزينها

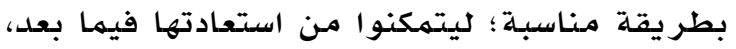
و النوع الثاني: الترميز التخيلي وفيه يكون الفرد تصورا عقليا وذهنيا عن موضوع التذور وهر وهو

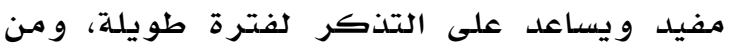

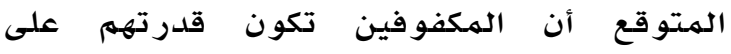

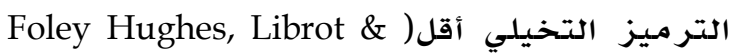

.(Paysnick, 2008, 831

كما أن تخزين المعلو مـات يته على عدة مراحل؛

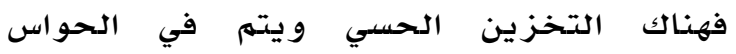

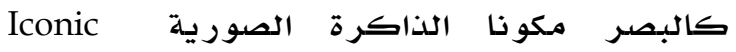
Echoic memory Memory

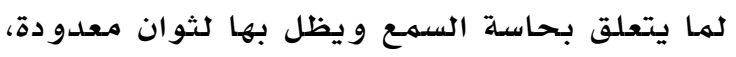
فإذا ركز الفرد على المثير ينتقل للذاكرة

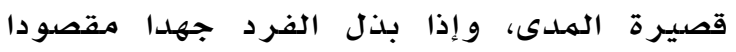
لحفظ المعلومـة تتحول للذاكرة طويلة المدىى

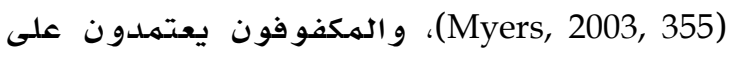

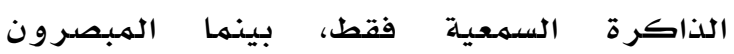
يستفيدون من الذاكرة البصر ية و السـمعية. مما سبق يتضح أن مهارات التجهيز السمعي تعد أسمات

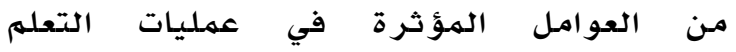

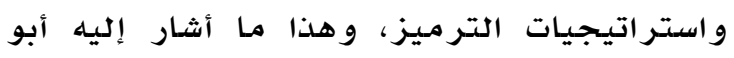

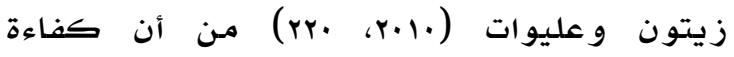
مهارات الاستماع تزيد من القدرة علدوات على التركيز

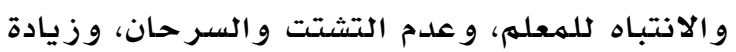

Bernstein, Beig, Siegenthaler, Grady, 2002, )

وهذا مـا أثارت إليه دراسـة ميلر و آخرون Miller, Donovan, Bennett, Aminoff\& Mayer, (2012) التي هدفت إلى التعرف على العوامل

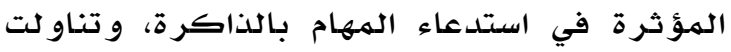

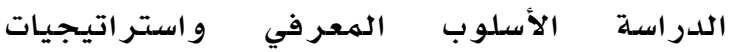

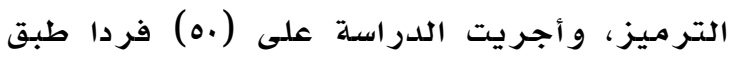

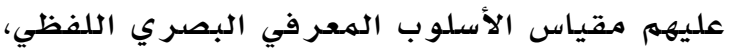

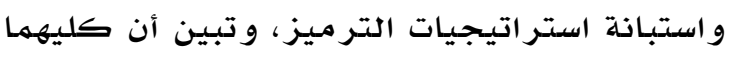
من العوامل الهؤثرة في التذكر، بيد أن تأثير

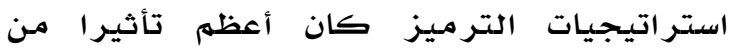

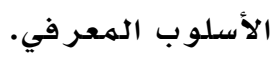

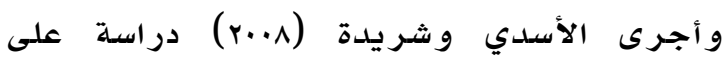

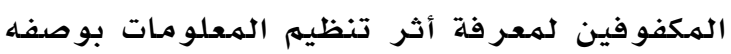

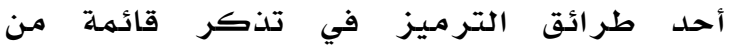

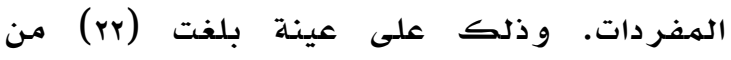

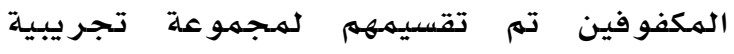

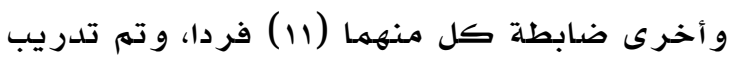

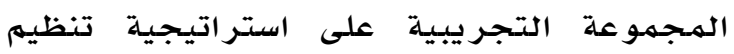

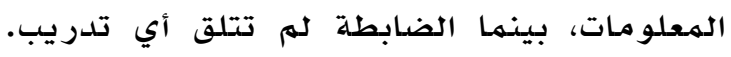
و عرض على الهـمهوعتين قائمسة مـ المفردات و طلب منهم حفظها، و في نهاية التجربة طلب من

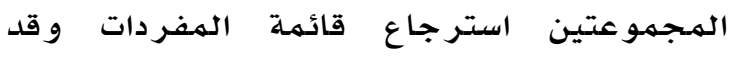

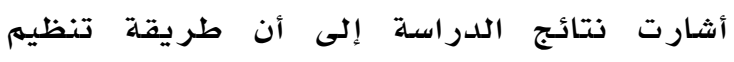

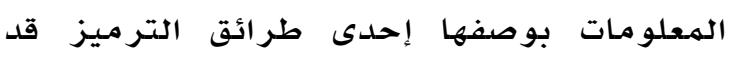

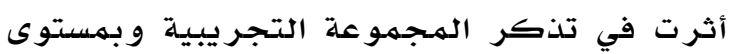

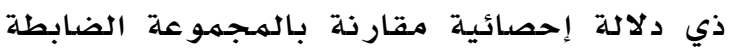
التي لهم تعط هذه الطريقة. و ترميز الهعلومات هو التجهيز الأو لي لها والذي

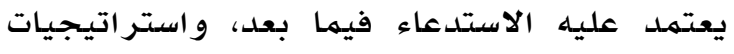

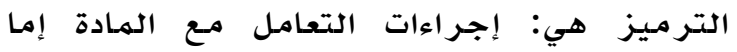

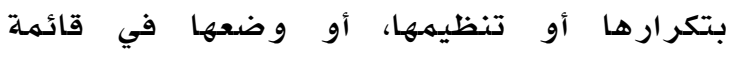

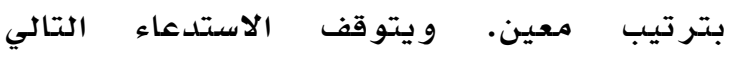

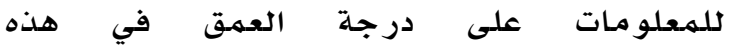

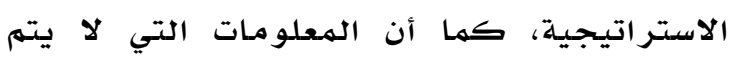
تر ميزها بطريقة جيدة يتم فقدها في مـر احل

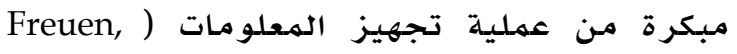
(2008, 7 
كما أن المعلومات التي يتم استقبالها بطريقة صحيحة يتم ترميزها بطريقة صحيحة أيضا، و قد اختلفت الدراسات السابقة في نتائجها حول كفاءة ترميز الهعلومات للدى المكفوفين

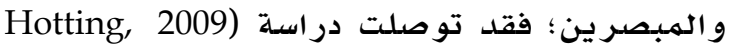
(\& Roder

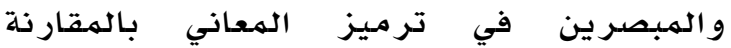

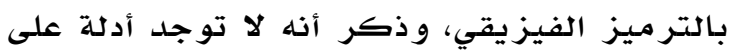
أن المكفوفين أكثر كفاءة في استخدام

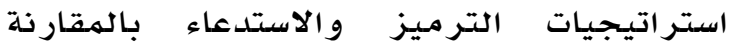

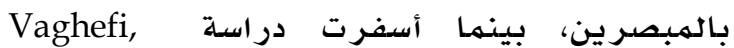
(Tehrani, Shirazi, Rezaei \& Rahgozar, 2013) عن تفوق عينة الهبصرين في التمييز

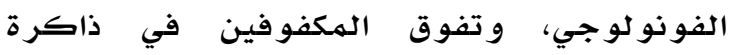

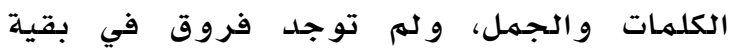

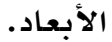

و بناء على ذلك تتحلدد مشكلة الدراسة في تعرف مستوى مهارات التجهيز السمعي للىى المكفوفين

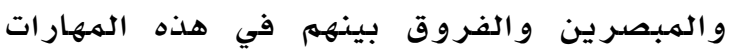
و استر اتيجيات التر ميز و عمليات التعله.

أسئلة الدراسة

تتحدد أسئلة الدراسلة فيما يلي:

ا. ما مستوى إتقان مهارات التجهيز السمعي لدى تلاميذ الهـرحلة الاعدادية المبصرين و المكفو فين؟

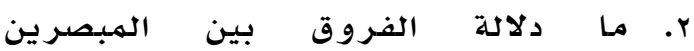
و المكفوفين في مهارات التجهيز السهعي، و استر اتيجيات التر ميز ، و عمليات التعله؟

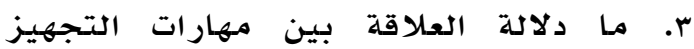
السمعي، و عمليات التعله؟ ع. ما دلالة العلاقة بين مهارات التجهيز السمعي، و استر اتيجيات الترميز؟

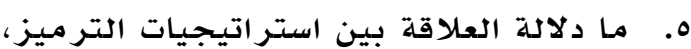
و عمليات التعلهم ؟ ماته

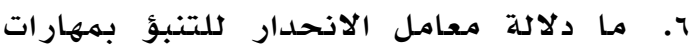
التجهيز السمعي من الدرجة على مقياسي:

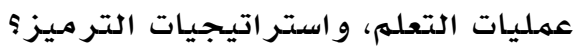

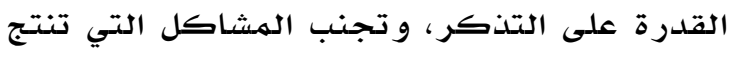
عن الفهم الخاطيء الناتج عن عدم الاستهاع الجيد، والاهتمـام المتبـادل من كلاء كلاء الطرفين؛

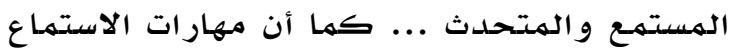
تشجع الآخر ين على المشار كة و إبداء الر أي. وبناء عليه فإن التعرف على مستوى مهارات التجهيز السمعي يفسر التباين في عمليات التعلم

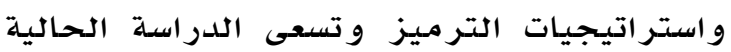
للتعرف على مستوى مهارات التجهيز السمعي لدى المكفوفين و المبصرين، وعلاقة ذلك بكل بكل من: عمليات التعلهم، و استر اتيجيات الترميز .

مشكلة الدراسة

عملية التعلم هي عملية متعددة الحواس، وقد أثبتت عديد من الدراسـات أن المـدخلات التي تعتمدد على حواس مختلفة تحسن مـن عملية الإدراك، وتسهل التحكم في الحدث. فمثلا رؤية

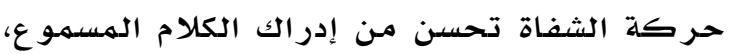
كما أن تعدد الحواس يجعل الحكم على الأشياء

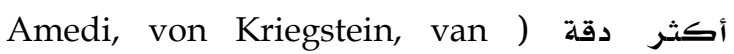
(Atteveldt, Beauchamp, Naumer, 2005

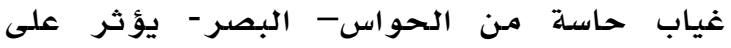
عمليات التعلهم التي يستخدمها الهكفوفون بالمقارنة بالعاديين الميان

ويعد استقبال المثيرات مـن خلال المدخلات

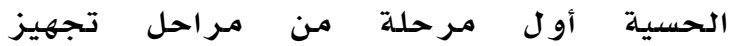

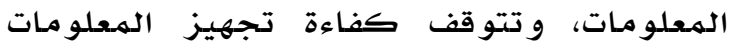

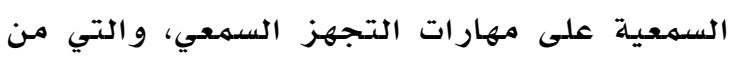
الهتوقع أن تختلف لدى المكفوفين عنها لدى لدى

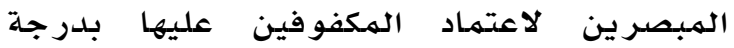
كبيرة برغم أن بعض الدراسات تشير لعدم وجود فروق بينهما في الذاكرة السمعية Collignon, Renier, Bruyer, Tranduy, Veraart, )

(2006

وقد أشار (Edwards, 2006) إلى أن مهارات التجهيز السهعي لهم تنل القدر الكافي من اهتهمام الباحثين رغم ارتباطها بكثير من مشكلات التعلهم؛

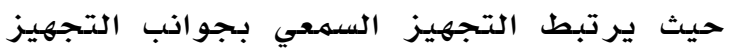
الأخر المى المعر في منها و الإدر اكي. 


\section{محددات اللدراسة}

تتحدد نتائج الدراسة الحالية بمتغيراتها و وعينتها

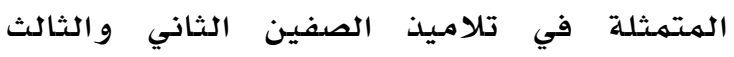

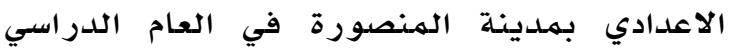

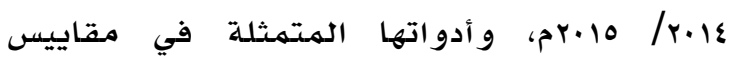

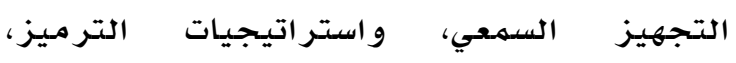

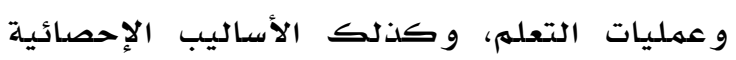

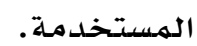

\section{المفاهيم الإجرائية للدراسة}

مهارات التجهيز السمعي: هي استقبال المثيرات

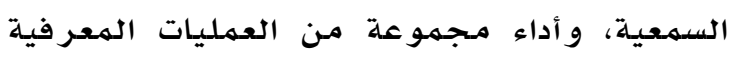

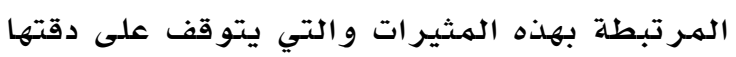

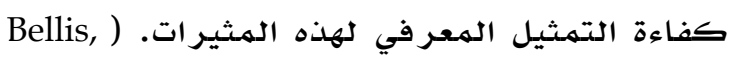

و تعرف إجرائيا في الدراسة الحالية بــ: قدرة

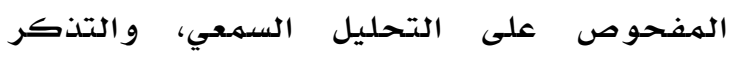

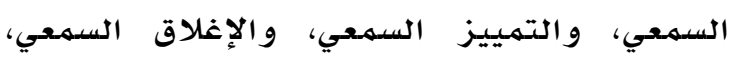

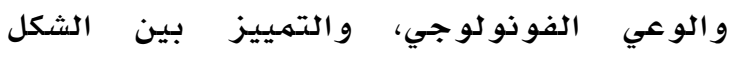

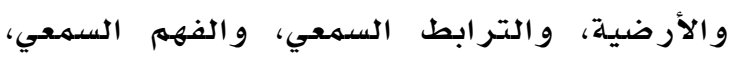

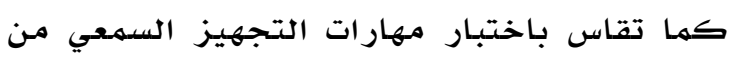

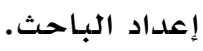

استراتيجيات الترميز: تشير إلى أنواع التلميحات

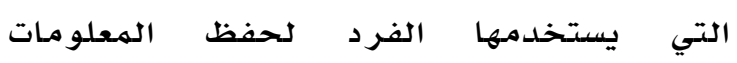

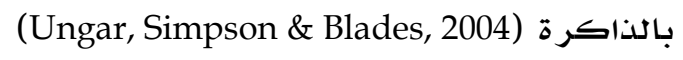
و تعرف إجرائيا بأنهـا: الإجـراءات التـي يتبعهـا

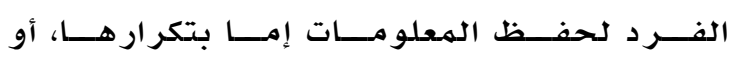

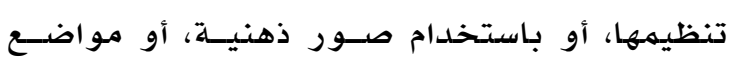

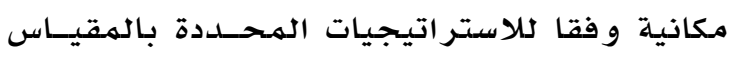

المستخدم بالدراسة الحالية من إعداد الباحث. عمليات التعلم: هي تلـك الاسـتراتيجيات التـي يفضلها الفرد ويستخدمها في معالجة المعلومات

حينما يواجه مهمة تعلهم. (Schmek, 1982, 73) و تعرف إجرائيا بأنهـا: الإجــراءات التـي يتبعهـ

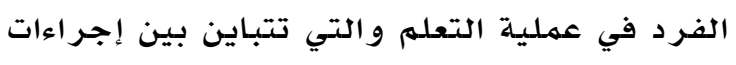

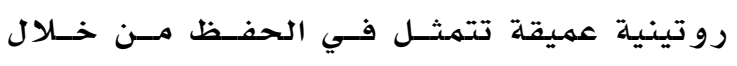

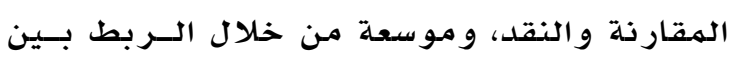

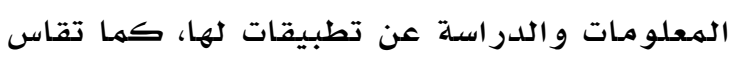

أهداف الدراسة

تهدف الدراسة الحالي إلى: الديه

ا- تعرف مستوى إلتقان مهارات الفئ التجهيز

السمعي لدى المبصر ين و المكفو فين.

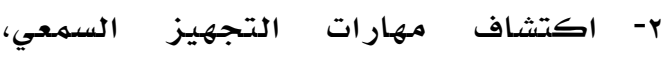

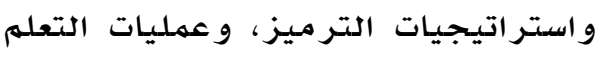

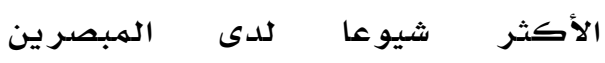
و المكفو فين.

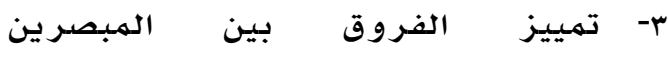
والمكفوفين في مهارات التجهيز

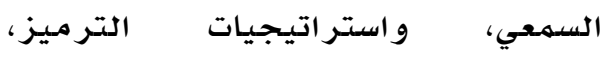

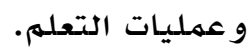

ع- فهم العلاقة بين مهارات التجهيز

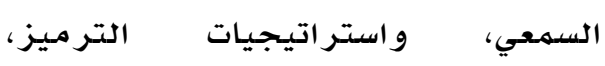
و عمليات التعلهم. والمعتر.

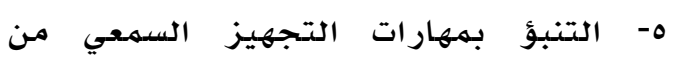

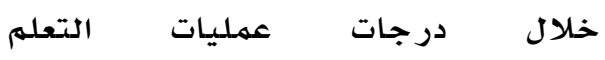
و استر اتيجيات التر ميز .

أهمية الدراسة

$$
\text { تتمثل أهمية الدراسة في: }
$$

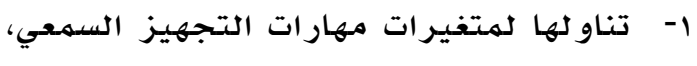

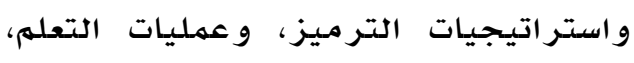

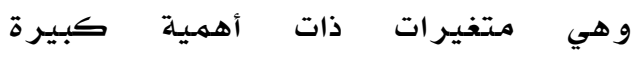

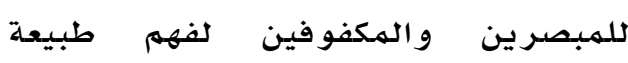
الفروق بينهم.

r- تناو لها لعينة المكفوفين وهي فئة تحتاج

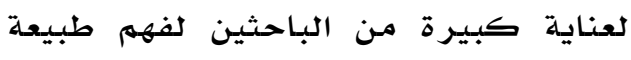
تعلمهم والفروق بينهم و بين العاديين. r- مقار نة المبصرين بالمكفوفين تفيد المعلمين في معرفة احتياجات كل كل من ونئن

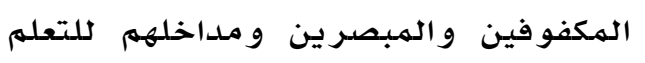
و وتوضيح أثر الخبرة في تجهيز المعلومات وملهات و التعله. ؟- يستفاد من نتائج هذا الدراسة لبناء برامجج

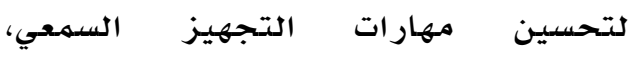
و استر اتيجيات التر ميز، و عمليات التعله. 
Corriveau, Pasquini \& Goswami, 2007)

(Edwards, $2006 \leq r \cdot 1$.

مر اجعة بعض الاختبارات التي تناولت مهارات

$$
\text { التجهيز السهعي، مثل: }
$$

Schow, Seikel, Brockett \& Whitaker, 2007; ) ( Iq9 ا Snell, 1992; Ormson, 1995;

تهم تحديد ثمان مهارات للتجهيز السهعي، هي: مهارة التحليل السهعي، وسعة الذاكرة السهعية،

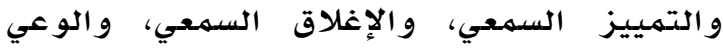

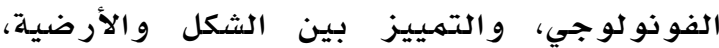

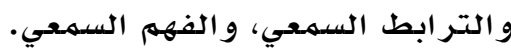

تم صياغة مـجموعة من الأسئلة التي تقيس كل

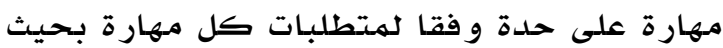

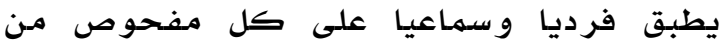
المبصر ين و المكفو فين.

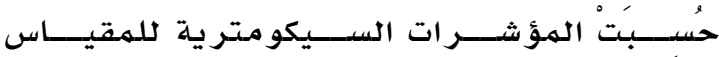

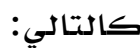

الصدق: اسـتخدمت طريقتـان لحســاب الصــدق، وهي:

صدق المحكمين؛ حيث عرض الباحث المقياس في

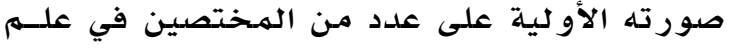

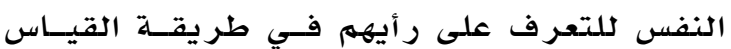
و مدىى منـاسـبتها للعينــة، وحسـذف أو إضــافة مـا

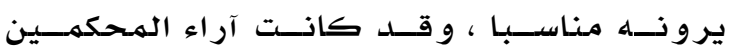
جميعها تلدور حول ضرورة اختصار المقياس قدر

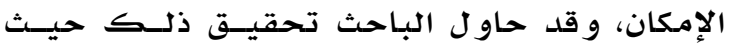
رفع نسبـة الاتفاق إلى ..1\%، حيث أبقى على مـا اتفق علية جميع المحكمين فقط. الصلدق المرتبط بالمحك

و فيه حسب معامل ارتباط سبير مان بـين درجـات

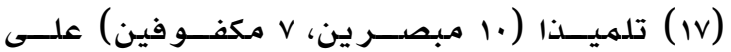
المقيــاس، ودرجــاتهم علــى مقيــاس الــــاكرة

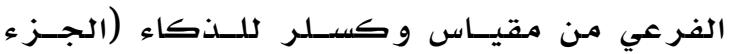

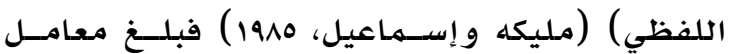

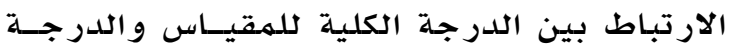

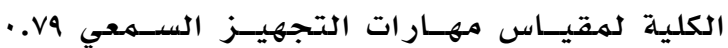
و هي قيمة دالة عند ال...
بمقياس عمليات التعلهم في الدراسلة الحاليـة مسن

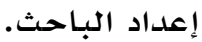

\section{الطريقة والإجراءات}

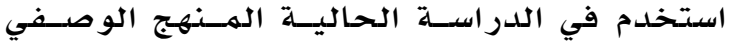

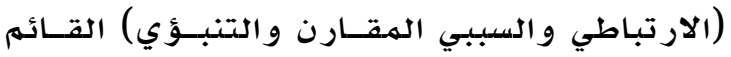

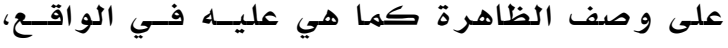

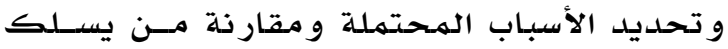

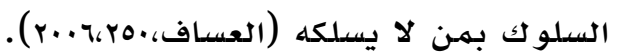

\section{مجتمع اللدراسة وعينتها}

تكــون مجتمـــع الدراســـة مــن جميــع الطــلاب الهبصرين مــن طلبــة الصــفين الثـاني و الثالـث

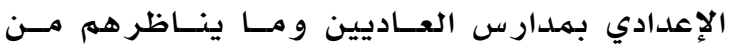
الطلاب المكفـوفين بهــدارس الأمهل للهكفــوفين نظرا لصعو بـة الحصول علـى عينــة كافيـة مسن المكفوفين بصف و احد ، و تكونت العينـة من (rv)

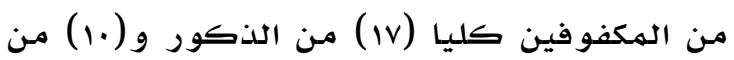

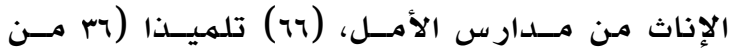

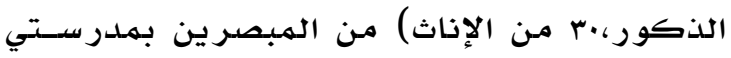

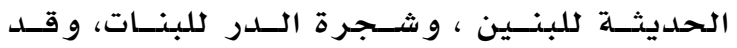

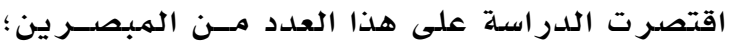
نظرا لصغر حجم عينة المكفوفين.

أدوات اللدراسة تمثلت أدوات الدر اسـة في:

مقياس مهارات التجهيز السـمعي وهو من

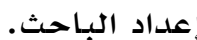

مقياس استر اتيجيات الترميز وهو من

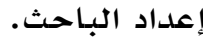

مقياس عمليات التعله وهو من إعداد

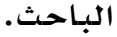

و فيما يلي ووصف لأدوات الدراسة، وطرق تقنينها: أولا: مقياس مهارات التجهيز السمعي: أعد المقياس و فقا للخطوات التالية: مراجعة الأدبيات التي تناولت مهارات التجهيز

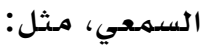




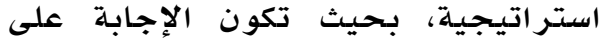

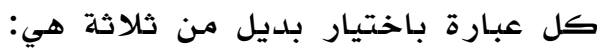

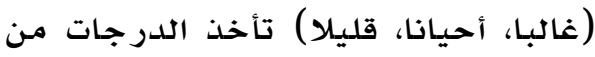

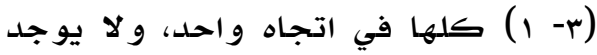
درجة كلية. وتطبق فرديا و وسماعيا على المكفوفين، وورقيا على المبصرين. تم تجميع الاستر اتيجيات المحددة تحت ثلاث استر اتيجيات كالتالي:

O استر اتيجيات روتينية: وتشهل

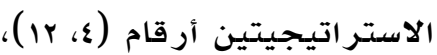

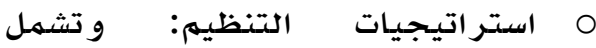

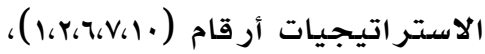

O

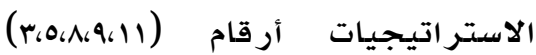

و ليس للمقياس درجة كلية.

حسب الباحث المؤشرات السـيكومترية للمقيـاس كالتالي:

المسدق

استخدمت طريقتان لحساب الصدق، وهي: صـدق المحكمـين: حيـث عُـرض المقيـاس فـي صدورته الأولية على عدد من المختصين في علــم

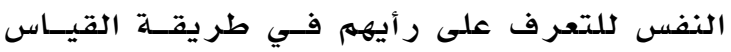

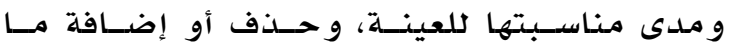
ير وذه مناسببا، و تمثلت تعسديلات المحكمهـين فـي ضبط بعض الصياغات اللغوية.

الصلدق المرتبط بالمحك:

وفيه حُسب ارتباط سـبير مـان بـين درجـات (IV)

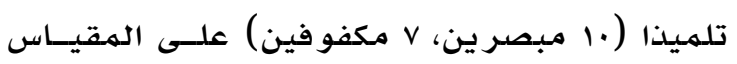

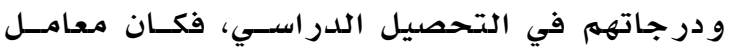

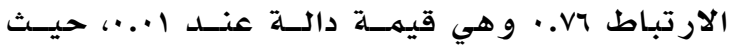

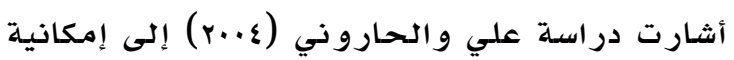
التتبؤ بالتحصيل الدراسي من خلال استر اتئجيات

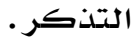

|نثبات

تم التحقق مـن ثبـات المقيـاس بطريقـة إعــادة التطبيق بفاصل زمنـي قدره 10 يومــا علـى عينــة

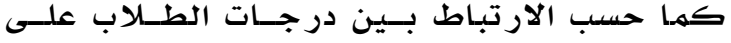
الهقياس ودرجاتهم في التحصيل الدراسـي فكسان

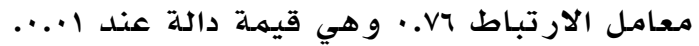
الثبات تم التحقق مـن ثبــات الهقيـاس بطريقـة إعـادة

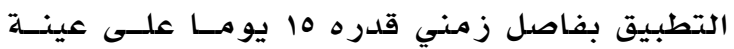

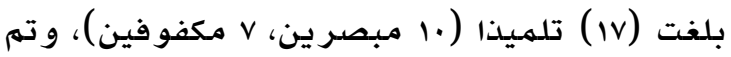
حســاب معامسل ارتبـاط ســبير مـان بـين درجــات

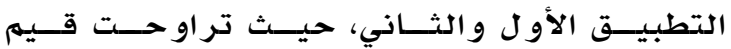
معــامـلات الارتبــاط والتــي تعبــر عـن الثبـــات

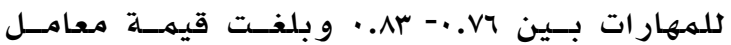
الارتباط للدرجة الكلية للمقياس هم. · وهي قـيم دالة عند مستوى ا+...، وتشير لهعامل ثبات مثالي

.(Robinson, Shaver \& Wrightsman, 1991, 62)

الاتساق الداخلي: حُسب معامل ارتباط سـبير مان

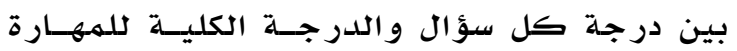
التي ينتهمي إليها، و كذلك ارتبـاط درجــة كـل

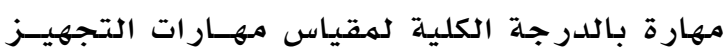
السمعي، وقد تر اوحت قيم معامـلات الارتباط بين

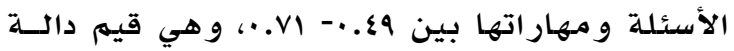

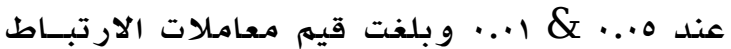

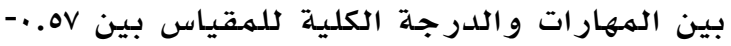

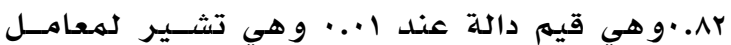
ارتباط مثالي. - إن

ثانيا: مقياس استراتيجيات الترميز، تم إعداد المقياس و فقا للخطوات التالية:

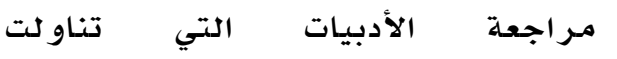

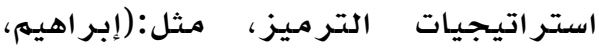
Bryan, Luszcz \& Pointer, 1999). ؟ ץ..V مر اجعة بعض الاختبارات التي تناولت بعض استر اتيجيات الترميز، مثل:

(Kirchhoff \& Buckner, 2006)

تم تحديد (r) استراتيجية لتترميز تشير إلى الطرق المختلفة التي يمكن

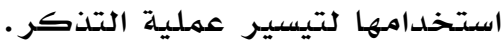

تم وضع (r) توصيفا لكل استراتيجية

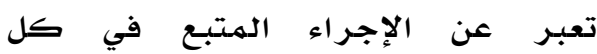


الصــدق، تــم التحقــق مـن الصــدق بطــريقتين كالتالي: صــدق المحكمـين: حيـث عُـرض المقيـاس فـي صدورته الأولية على عدد من المختصين في علـهم

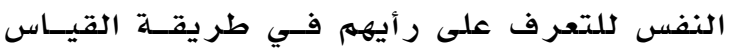

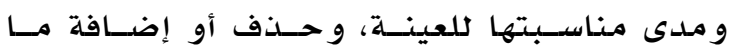
يرونه مناسبـا، وتمثلت تعـديلات المحككمسين فـي

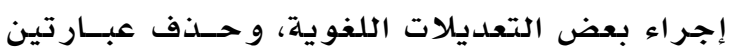
اتفق بعض المحكمين على عدم وضوحهما. صدق التحليل العاملي و فيـه طبـق الهقيـاس علـى (r.v) تلاميـذ مــن

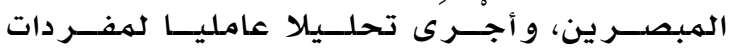
الهقياس و تم التأكد من صدلاحية البيانات لإجر اء لهري

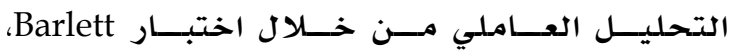

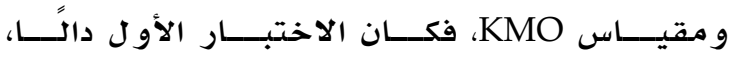

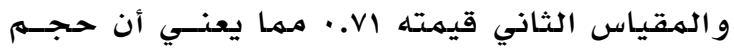

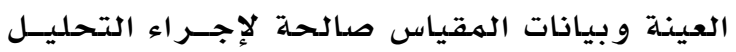

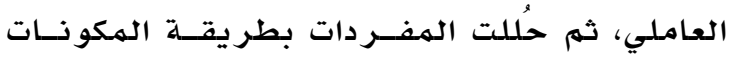

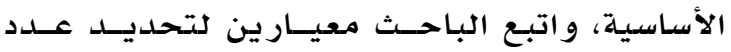

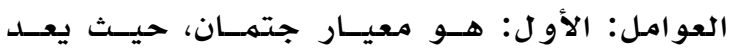

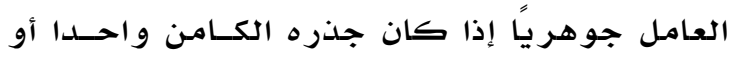

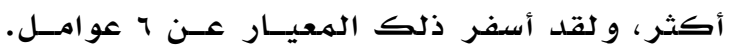
الثاني: مخطط الانحدار Scree plot و فيه فحص الر سهم البياني للمنـحنى الذي يصف العوامل وعند وعند

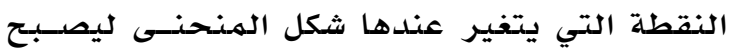

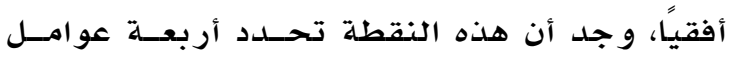

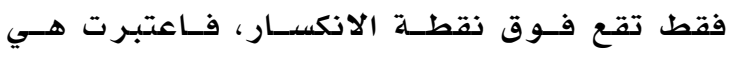

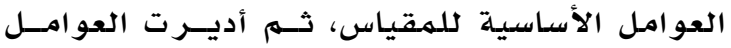

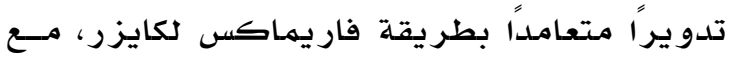
تحديل أربعسة عوامـل فقـط للتحليـل، وأخـــت المفردات التي يكون تشـبعها م. · فـأكثر ، ونـتج

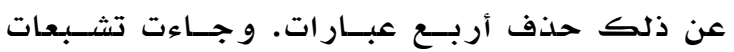
المفردات على العوامل كما بجدول ال إن
بلغت (IV) تلميذا (.l مبصر ين،V، مكفوفين)، و تم حسـاب معامـل ارتبـاط ســبير مـان بـين درجـــات

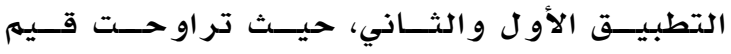
معاملات الارتباط بين التطبيقـين الأول و الثـاني

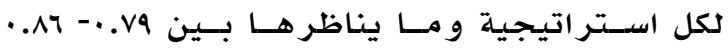

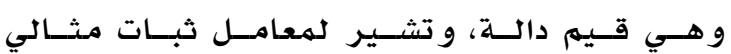

.(Robinson, Shaver \& Wrightsman, 1991, 62)

الاتسـاق الداخلي

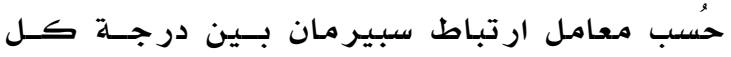
مفردة و الدرجـة الكلية للاستر اتيجية التي ينتمي إليها، وقد تراوحت قيم معـاملات الارتبـاط بـين وهين

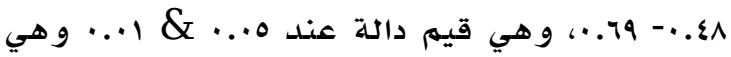
تشير لمعامل ارتباط مقبول. لو له

ثالثا: مقياس عمليات التعلم: تم إعداد المقياس وفقا للخطوات التالية:

مراجعة الأدبيات التي تناولت عمليات

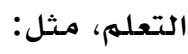

Offir, Lev \& Bezalel, 2008, Pan \& )

( Hawryszkiewycz, 2004 مر اجعة بعض الاختبارات التي تناولت

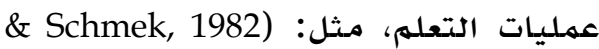

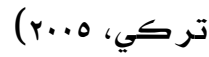

تم التوصل إلى أربع عمليات من عمليات

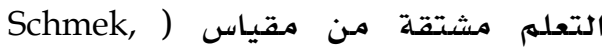
1982) وهي: العمليات العميقة، وعمليات الحفظ، وعمليات الدراسـة، والعمليات

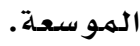

وضعت مجمو عة مـن العبارات بلغت (VY) مفردة لكل العمليات، بحيث تكون الإجابة على كل عبارة باختيار بديل من ثلاثة

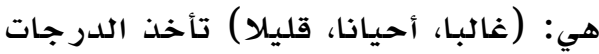

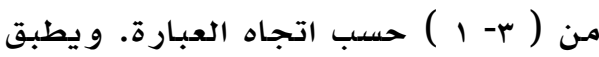
فرديا و سماعيا على المكفوفين ووروقيا على الهبصرين، وليس للهقياس درجة كلية.

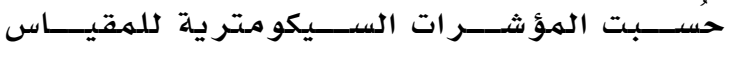
كالتالي: 


\section{جدول ا}

قيم تثبعات المفردات على عواملها والتباين والجذر الكامن

\begin{tabular}{|c|c|c|c|c|c|c|c|c|c|}
\hline \multicolumn{4}{|c|}{ العوامل } & \multirow[t]{2}{*}{ p } & \multicolumn{4}{|c|}{ العوامل } & \multirow[t]{2}{*}{ r } \\
\hline الرابع & الثالث & الثاني & الأول & & الرابع & الثالث & الثناني & الأول & \\
\hline- & ... & - & - & $r \varepsilon$ & - & . . & - & - & 1 \\
\hline r.. & - & - & - & ro & - & - & - & .rq & $r$ \\
\hline .rq & - & - & - & ד & - & - & .. $\{\leqslant$ & - & $r$ \\
\hline$\therefore \leqslant 0$ & - & - & - & rV & - & .01 & - & - & $\varepsilon$ \\
\hline- & T & - & - & $r_{\Lambda}$ & - & - & ג . . & - & 。 \\
\hline- & - & ..$\varepsilon \wedge$ & - & rq & - & - & - & .01 & 7 \\
\hline- & - & - & .01 & $\varepsilon$. & - & - & . . & - & v \\
\hline$\therefore \leqslant \wedge$ & - & - & - & $\varepsilon 1$ & - & .rq & - & - & $\wedge$ \\
\hline- & - & ع & - & $\varepsilon r$ & r & - & - & - & 9 \\
\hline- & - & - & r & $\varepsilon r$ & - & rr. & - & - & 1. \\
\hline- & - & rז. & - & $\varepsilon \varepsilon$ & - & .. & - & - & 11 \\
\hline- & .. & - & - & $\leq 0$ & גז.. & - & - & - & ir \\
\hline- & - & - & . . & $\leq 4$ & - & $\ldots \varepsilon$ & - & - & ir \\
\hline- & - &..+9 & - & $\varepsilon V$ & . or & - & - & - & $1 \varepsilon$ \\
\hline .. & - & - & - & $\leq \lambda$ & - & - & - &.$r q$ & 10 \\
\hline- & A & - & - & $\leq 9$ & - &.$r V$ & - & - & 17 \\
\hline- & - & - & .00 & 0 . & - & - & זr.. & - & iv \\
\hline..$\leqslant \wedge$ & - & - & - & 01 & - & - &..$\leq \varepsilon$ & - & 11 \\
\hline- & - & - & rr. & or & - & - & - & .01 & 19 \\
\hline- & . . & - & - & or & .. $\varepsilon q$ & - & - & - & $r$. \\
\hline- & & - & - & $0 \varepsilon$ & - & - & ג & - & $r$ \\
\hline- & - & ... & - & Do & - & - & - & .. $\varepsilon 1$ & r \\
\hline- & - & - & rr. & 07 & - & - & - &.$r V$ & r \\
\hline- & - & ... & & ov & . . & - & - & - & r \\
\hline- & - & - & .00 & 01 & - & - & זr.. & - & ro \\
\hline- & . . & - & & 09 & - & - & - & גז. & Y \\
\hline- & & - & .. $\leqslant 1$ & 7. & - & - & 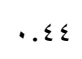 & - & TV \\
\hline- & r & - & - & $\pi$ & - & - & - & .01 & rA \\
\hline . . $\leqslant Y$ & - & - & - & Tr & - & - & - &. .71 & rq \\
\hline- & rr. & - & - & זד & - & . . हr & - & - & $r$. \\
\hline- & ... & - & - & $T \varepsilon$ & .01 & - & - & - & r \\
\hline- & - & - & דז.. & 10 & .07 & - & - & - & rr \\
\hline . & - & - & - & 4 & - & - & - & .. $\leqslant \varepsilon$ & rr \\
\hline$\wedge . \wedge$ & 9.9 & $1 . . v$ & ir & & & & & & \\
\hline K.T & |ะ..1 & $10 . r$ & IV.I & & & & & & \\
\hline
\end{tabular}

الهقارنات، و التوصل لجوانب الضـعف و القصــور

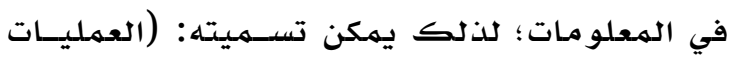

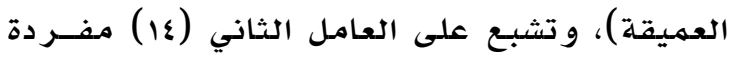

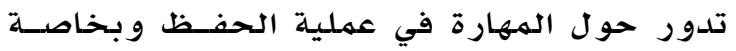

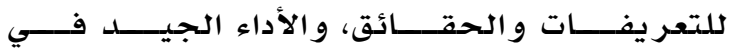

يعرض جلدول ا نتائج التحليـل العـاملي والـذي

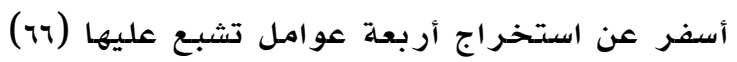

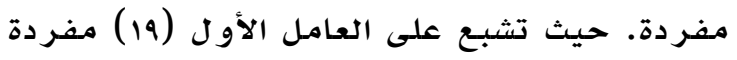

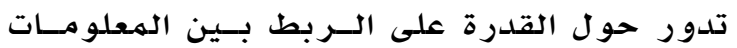

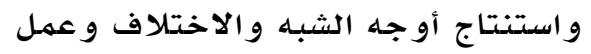




\section{عرض النتائج ومناقشتها}

النتائج المتعلقة بالسؤال الأول: ما مستوى إتقان مهارات التجهيز السمعي للى تلاميذ المرحلة الإعدادية المبصرين والمكفوفينء

لإِجابة على هذا السؤال تم استخدام اختبار (ت)

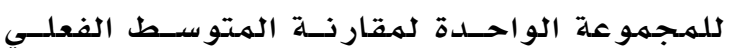
بالمتوسط الفر ضي الـذي يتحسـدد بدرجسـة .0 \%

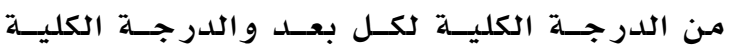

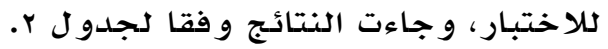
يعــرض جــدو ل ب قيمـــة (ت) للفــروق بــين المتوسطين الفعلي و الفرضي في مهارات التجهيز

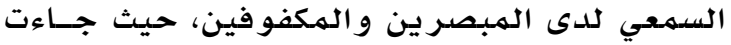
دالة في جميع الأبعاد لدى المهجموعتين في اتجاه المتوسط الفر ضي، ما عـدا بعسـد سـعـة الــذاكرة

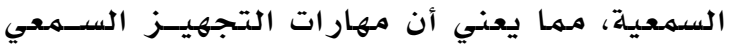

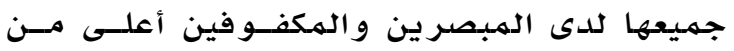
الهتوسط باستثناء سعة الذاكرة الســمعية، فهـي أقل من المتوسط لدى المبصرين ومتوسطة لدى الدى المكفوفين، و تشير هذه النتيجهة إلـى أن مهــارات

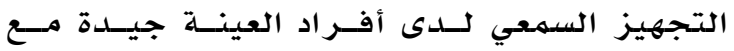
اعتماد معظم الأنشطة الحياتية و الملدرسـية علـى

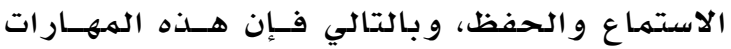
تتطور، فالطالب في المدرسة وسلة لابد أن يتذكر مـاكس يسمعه جيدا، و عليه أن ينظمه ليتمكن من كتابته

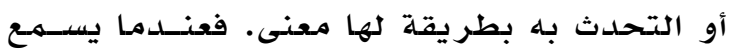
الإنسـان يكتسب لغــة مســمو عة، و عنـــمـا يحــاول تقليدها فهو يستخدلم لغتته المسموعة ليكون لغسـة

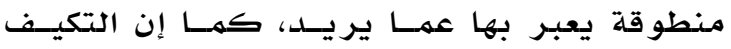
الاجتماعي لا يأتي من فراغ، فهو بحاجة للتفاعل

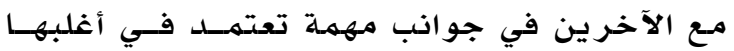

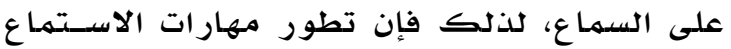

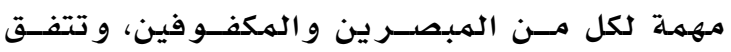

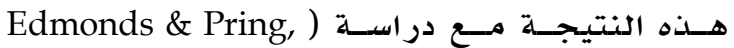

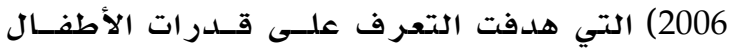
المكفو فين بالمقار نة بالمبصرين في القدرة على الاستيعاب السمعي للنصوص، و تكوين الاستنتاجات

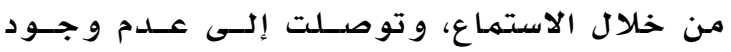
فروق دالة بينهما، ووكان المكفو فون والهبصـرون ولدون
الاختبار ات، و أداء الواجبات بكل دقة، لذلك يمكن

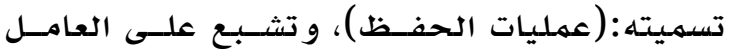

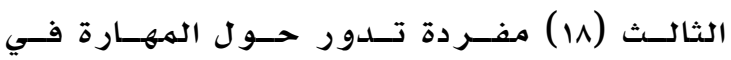
التخطيط لعملية المـاكرة بتنظـيم الهعلومسات

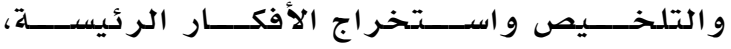

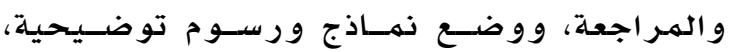

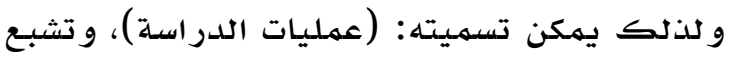

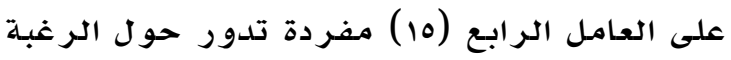
في الاستزادة من المعلو مـات و البحث عن تطبيقات جلديدة لهما يتعلمهه وربطه بهواد آخرى، و تفضـيل

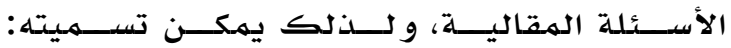
(العمليات الموسعة))، وبناء على ذلك ولى فقد أصدبـح

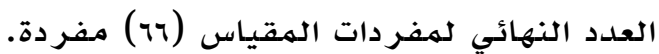

الثبات: تم التحقق من ثبـات الهقيـاس بطريقـة

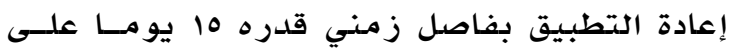

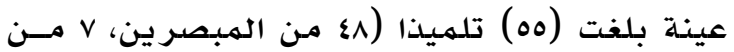

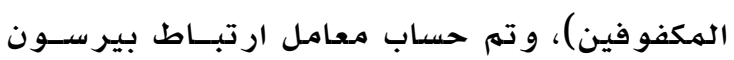

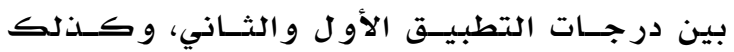
بطريقــة ألفاكر وونبـاخ، حيسث تر اوحسـت قـيـم

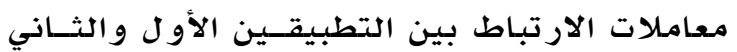

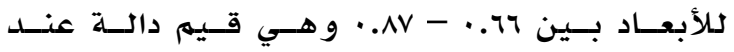
مستوى ا+..، وتشير لمعامل ثبـات مثـالي، كهـا حســب الثبــات أيضــــا بطر يقـــة ألفاكر وونبـــاخ،

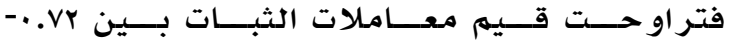
1 ^.•و هي تشير لثبات عالي للهقياس. الاتساق الداخلي: حسب معامل ارتبــاط بيرسـون

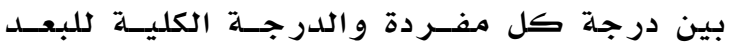

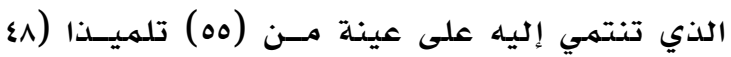

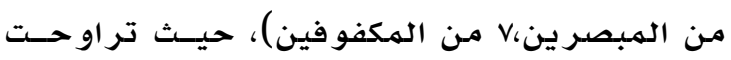

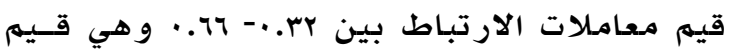

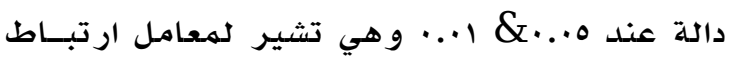

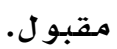

الأساليب الإحصائية: تم استخدام اختبار (ت) للمسجموعة الواحدة، واختبـار تحليل التبـاين متعددد

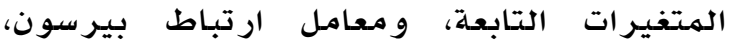
و معامل الانحدار المتعددد. 
جدولن

مستوى مهارات التجهيز السمعي لدى المكفوفين والمبصرين

\begin{tabular}{|c|c|c|c|c|c|c|}
\hline مستوى الدلالة & قيمة (ت) & المتوسط الفرضي & الانحراف المعياري & المتوسط الفعلي & المجموعة & البعد \\
\hline$\cdots 1$ & Ir.IT & r.o & 1.15 & $\varepsilon .1 V$ & مبصرون & مهارة التحليل السمعي \\
\hline$\cdots 1$ & $1 \wedge .1$ & &. .01 & $\varepsilon .0 Y$ & مكفوفون & \\
\hline$\cdots+1$ & r.99 & 9 & r.11 & A.r. & مبصرون & سعة الذاكرة السمعية \\
\hline غير دالة & $\because V V$ & & 1.99 & q.r. & مكفوفون & \\
\hline$\cdots 1$ & $11 . r 9$ & 0 & $1 . V T$ & $\vee . \varepsilon 1$ & مبصرون & التمييز السمعي \\
\hline$\cdots+1$ & $1 \leqslant .9$ & & $1 . .7$ & $\wedge . . \varepsilon$ & مكفوفون & \\
\hline$\cdots+1$ & rv.o & r.o & זד. & $T . \varepsilon r$ & مبصرون & الإغلاق السمعي \\
\hline$\cdots+1$ & $\varepsilon . r$ & & r...r & 0.19 & مكفوفون & \\
\hline$\cdots+1$ & $1 \cdots v$ & r & $1 . \varepsilon 1$ & $\varepsilon .10$ & مبصرون & الوعي الفونولوجي \\
\hline$\cdots \cdot$ & Tr.t & &. .01 & $0 . \leqslant \Lambda$ & مكفوفون & \\
\hline$\cdots 1$ & 9.1 & r & 1.17 & r.rq & مبصرون & التمبيز بين الثكل والأرضية \\
\hline$\cdots 1$ & rv.o & &.$r V$ & $r .9 r$ & مكفوفون & \\
\hline$\cdots 1$ & r..r & 0 & $1 . r 0$ & 1.00 & مبصرون & التزابط السمعي \\
\hline$\cdots+1$ & $\varepsilon . r$ & & T.T. & $v .10$ & مكفوفون & \\
\hline$\cdots+1$ & 17.9 & r & $\because .99$ & 0.17 & مبصرون & الفهم السمعي \\
\hline$\cdots+1$ & r.TV & & $1 . \varepsilon 1$ & $\varepsilon \ldots$ & مكفوفون & \\
\hline$\cdots+1$ & V. $9 \varepsilon$ & r & $\because .99$ & r.qV & مبصرون & ذاكرة الجمل \\
\hline$\cdots \cdot 1$ & $11 . \wedge r$ & & $.7 \varepsilon$ & T. $\varepsilon \varepsilon$ & مكفوفون & \\
\hline$\ldots 1$ & rV.19 & זr & $0 . r 0$ & 0.91 & مبصرون & الدرجة الكلية \\
\hline$\ldots 1$ & $1 \wedge .1$ & & $\varepsilon .91$ & $01 . . \varepsilon$ & مكفوفون & \\
\hline
\end{tabular}

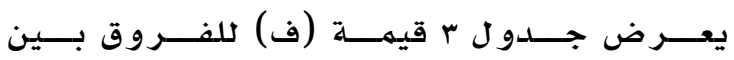

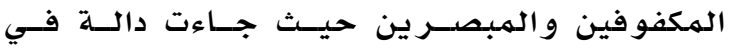
معظم الأبعاد مـا عدا مهارتي: التحليـل و التمييـز السـمعي، و الدرجــة الكليــة لمهــار ات التجهيـز

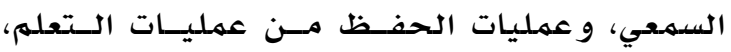
و الاسـتر اتيجيـات الرووتينيــة مــن اســتر اتيجيات الترميز، و للتعرف على اتجاه الفروق تم حسـاب

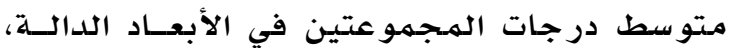

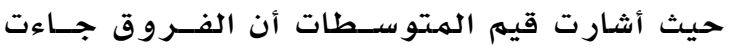
في اتجاه الهبصرين في مهارات: الإغلاق السمعي، و التر ابط السمعي، و الفهم السمعي، ووكانـت فـي لهـي اتجاه المكفـوفين فـي مهــارات: سـعـة الــذاكرة

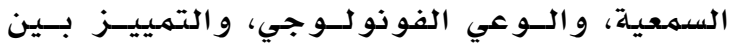

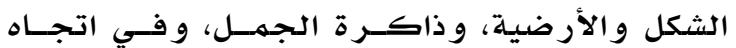

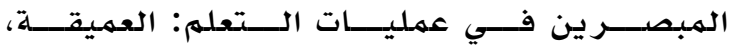
و الموسعة، و طرق الدر اسـة، ووفي اتجاه المبصرين

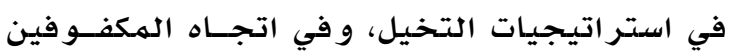
في استر اتيجيات التنظيه.
قادرين على عمل الاستنتاجات من لال الاستمـاع.

النتائج المتعلقة بالسؤال الثاني: ما دلالة الفروق بين المبصرين والمكفوفين في مهارات التجهيز السمعي? لاختبـار هـذا الفـرض اسـتخدم الباحسث تحليـل التباين متعـدد المتتغيـر ات التابعـة (MANOVA) للوقوف على الفروق بين المكفوفين والمبصرين

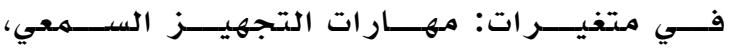

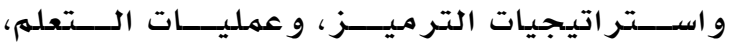
و لاختبار صلاحية البيانات لتحليل التباين جـاءت قيهم اختبار ليفـين Eير دابـة مهــا يشـير لتجــانس التباين وكانت قيمسة Wilks' Lambda تســاوي

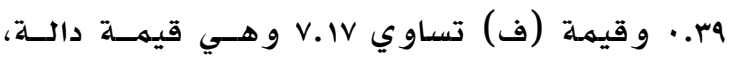

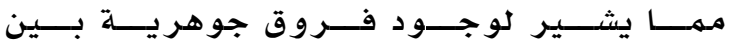

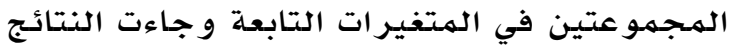
كما بجدو له. 


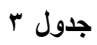

قيمة (ف) ودلالتها لتحليل التباين متعدد المتغيرات التابعة للفروق بين المبصرين والمكفوفين

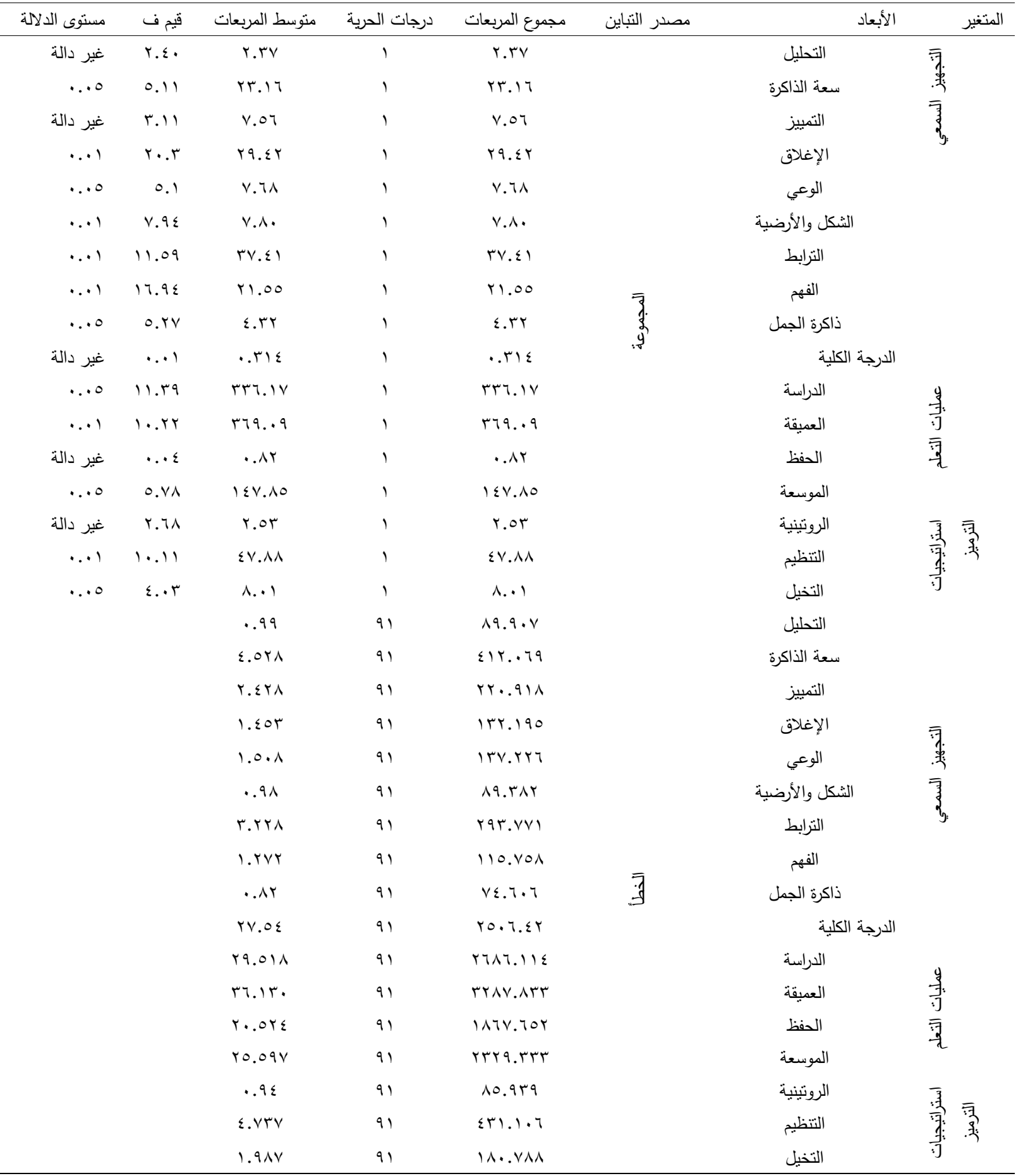

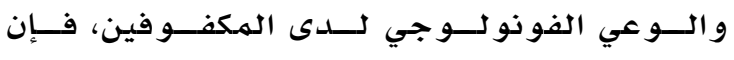

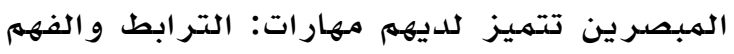

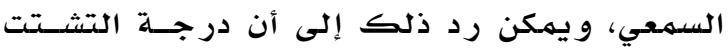

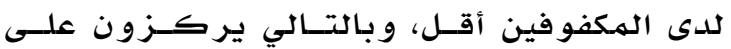

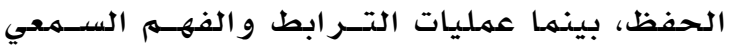
تعتمدد على تكامل أكثر مـن حاسلة و لذلك تميـز بها الهبصرون، كها أن سعي الهكفوفين لتوظيف
و تشير هذه النتيجة إلى وجود تقارب إلى حدّ مـا

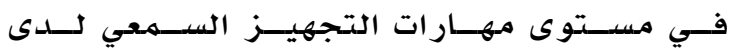

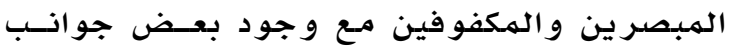

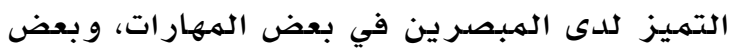
جوانب التمـيز لدى المكفوفين؛ ففي الوقت الـذي لـي تتطور فيه مهارات سعة الذاكرة وذذاكرة الجمهل 
تحسن من عمليـة الإدرالك، وتسـهل الـتحكم فـي

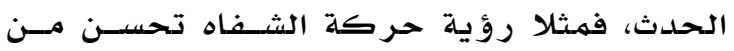

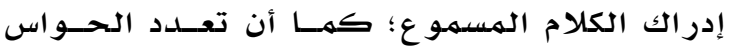

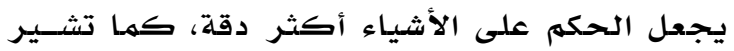

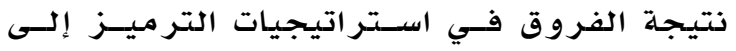
تميز عينة المبصرين على المكفوفين فسي بعـض التهري

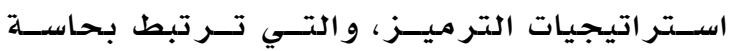
البصر، مثل: تكوين الصدور الذهنية، أو الاحتفاظ

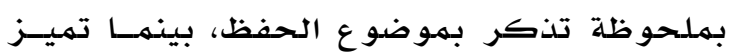

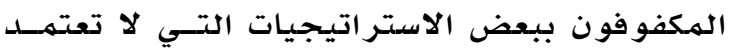

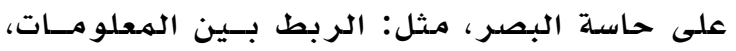
و تصنيف عناصر الهموضوع في مجمهو عات. كما أن هذه النتيججة تشـير إلـى أن المكفـوفين

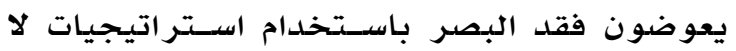
تعتمدد عليه، كاستر اتيجية التنظيم التـي تعتهــد على تصنيف المعلو مات أو ترتيبها بشـكل يســهل المهل

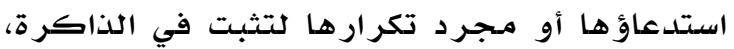

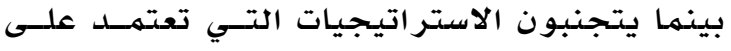

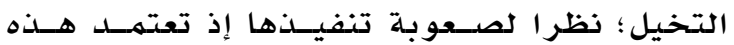
الاستر اتيجيات على تكوين صور أو تصور مواقف

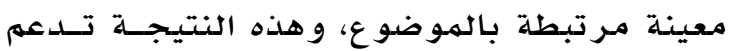

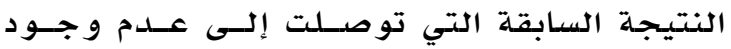
فروق بين العاديين و المكفوفين في بعض مهارات

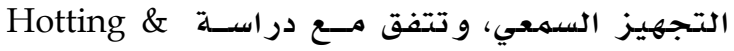

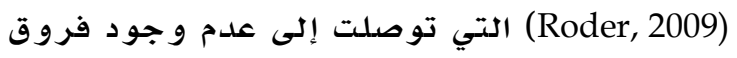

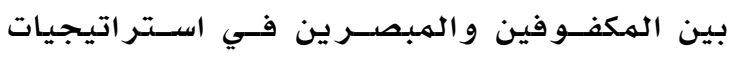

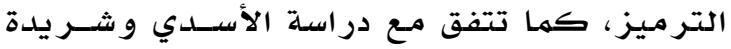

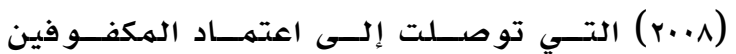
بدرجة كبيرة على استر اتيجية التنظيه .

النتائج المتعلقة بالسؤال الثالث: ما دلالة العلاقة بين مهارات التجهيز السمعي وعمليات التعلم؟

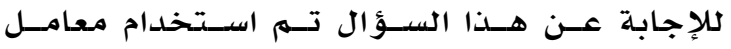

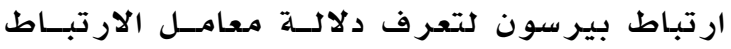
بين مهارات التجهيـز السـهعي و عمليـات الـتعلم

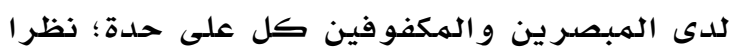
لوجود فروق بينهها، وجاءت النتائج وفقا لجدول
السهـع بطريقة أفضل يجعلهم أكثـر تميـزا فـي إنها

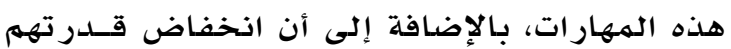
على التخيل الهببني على حاســة البصـر يجعلهـهم

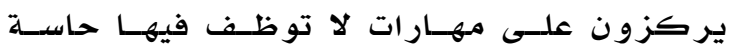

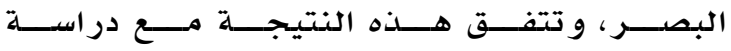
(Hotting \& Roder, 2009) و جود فروق بين المكفو فين والمبصر ين في مهام الاستدعاء، ودر اسلة ( Akpinar, Popovi \& Kirazci,

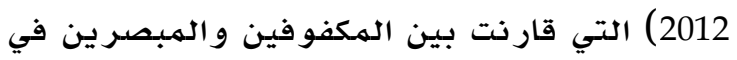

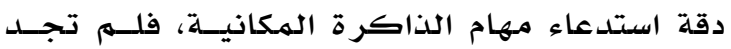

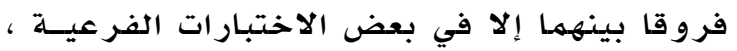

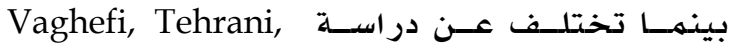
(Shirazi, Rezaei \& Rahgozar, 2013) إلى تفوق الهـبصـر ين فـي الـو عي الفونو لــوجي، بينما تتفق معها في تفوق المكفوفين في ذاكــرة

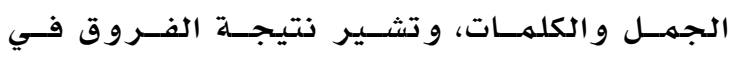
عمليات التعلهم إلى تفوق المبصرين فـي عمليـات التعلم على المكفوفين في كل عمليات التعلم مـا عدا عمليات الحفظ، فعمليات التعلهم تعتهـــ علـى الهى تعدد الحواس؛ و البصر من أكثر الحواس ارتباطا

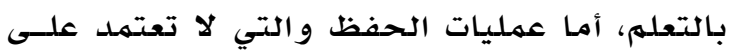
البصر بلدرجـة كبيرة فلهم تكن الفروق فيها دالـة

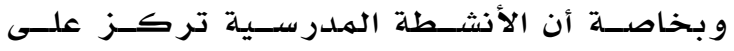

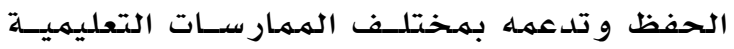
من التــدريس إلـى التقـويهم، كهــا أن العمليـات

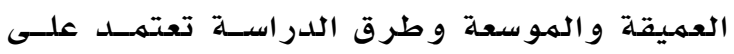

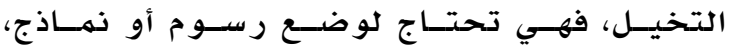

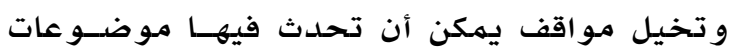

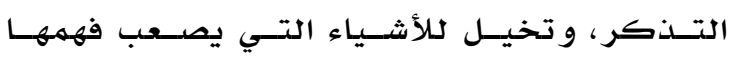
وربطها بما هو معروف للطالـب، والتفكيـر فـي

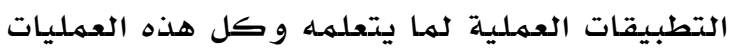

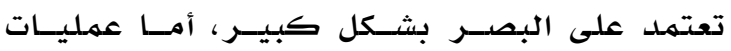
الحفظ فيمـارسها المبصرون والمكفوفـون؛ فهـهم يعمدون إلى التكر ار و المـر اجعـة لحفظ المعلو مـة،

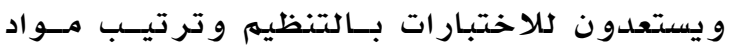
Amedi, ) الدراسة، و يلدعم هذه النتيجة ما ذكره vonKriegstein, vanAtteveldt, Beauchamp, مـن أن عملية التعلهم هــي عمليـة (Naumer, 2005

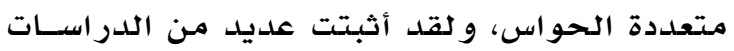
أن المداخلات التتي تعتمــد علـى حسـواس مختتلفـة 
جدول ؛

قيم (ر) ودلالتها لمعاملات الارتباط بين مهارات التجهيز السمعي وعمليات التعلم

\begin{tabular}{|c|c|c|c|c|c|c|c|c|}
\hline \multirow[b]{2}{*}{ الموسعة } & \multicolumn{2}{|c|}{ المكفوفون (rv) } & \multirow[b]{2}{*}{ طرق الدراسة } & \multicolumn{3}{|c|}{ المبصرون (ד 7) } & \multirow[b]{2}{*}{ طرق الدراسة } & \multirow[t]{2}{*}{ مهارات التجهيز } \\
\hline & الحفظ & العميقة & & الموسعة & الحفظ & العميقة & & \\
\hline .11 &.$r q$ & $.1 \mathrm{~V}$ & UrV & $* * .0 \mathrm{~V}$ & ${ }^{*} \cdot Y_{Y}$ & $* * \ldots 1$ & $\because .49$ & التحليل السمعي \\
\hline *.rq & $\because \leqslant 0$ & *.r人 & *.rq & .19 & $* * .00$ & $\because \mu$ & $* * .09$ & سعة الذاكرة السمعية \\
\hline.$r q$ &.$r 4$ & .017 &. ro & $* * . . \leq r$ & $*$ *. & דr." & $\because r$. & التمييز السمعي \\
\hline. .41 & .19 & .11 & .10 &..$r$ & $* . .49$ &. .11 & .11 & الإغلاق السمعي \\
\hline 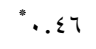 & .19 & *. & *.r人 & ".rq & *. & $\because Y V$ & *. ro & الوعي الفونولوجي \\
\hline תז. & 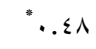 & $.1 \leq$ & $* \leq V$ & $. r \leq$ & " & $.1 \leq$ & $* *$ *.$\leqslant 7$ & الشكل والأرضية \\
\hline$*$ *.$\leqslant r$ & $* \leq 1$ & . rr & *..$\leq \leq$ & ** & $* * .01$ & *. $.0 \mathrm{~V}$ & "r." & الترابط السمعي \\
\hline$* * .00$ & $\because \leq \leqslant 0$ & *. & *.rq & $* * .71$ & $* * .00$ & $\because r q$ & $* * . . \leq 9$ & الفهم السمعي \\
\hline$*$ & $* * .0 r$ & *.r人 & $* . r q$ & $* * \ldots \leqslant$ & $* * .01$ & $* *$. & ** . & ذاكرة الجمل \\
\hline$* * .09$ & $\because . \leqslant V$ & * . . $\leqslant \varepsilon$ & $* * . . \leqslant 9$ & ${ }^{* *} \cdot . \leqslant 9$ & ${ }^{* *} \cdot .0 \mathrm{~V}$ & $* * .7 r$ & ${ }^{* *} . .01$ & الدرجة الكلية \\
\hline
\end{tabular}

ذلــك مــا ذكــره (Freuen, 2008, 7) مسـن أن

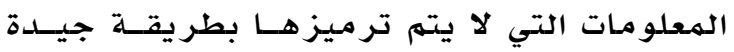
يتمر فقدها في مـراحل مبكرة من عمليـة تجهيـز

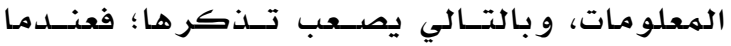
يوظف الطالب حواسـه وقدر اته بطريقة جيدة في

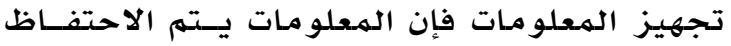
بها لفترة طويلــة، كمــا تتفـق مــع مــا ذكــره (Brigitte, Frank \& Neville, 2001, 289) يتوقع أن البناء المعرفي للكفيـف يختلـف عـن

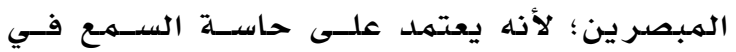

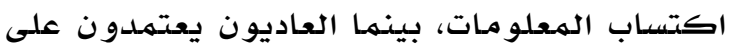

" القيمة دالة عند مستوى دلالة ه. ...

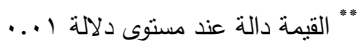

يعرض جدول ع معاملات الارتباط بـين مهـارات التجهيز السهعي و عمليات التعلم حيث يتضح أنها موجبـة دالة في معظمها و بخاصدة: مهـارات سـعـة الذاكرة السـهعيـة، والتــر ابط السـهمي، و الفهـهم السمعي، و ذاكرة الجهل، و الدرجة الكلية لههارات

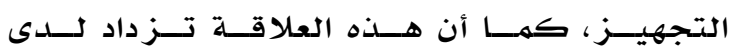
المبصر ين؛ نظـر ا لحسـدوث تكامسل بـين حاسـتي

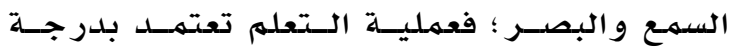
كبيرة على السهمع، فمعظم وقت الدراسة يقضيه الطالب في الاستماع لذلك فهو ضروري لتطوير عمليات التعلهم، كما أن حدوث الدهاب التكامل بين السهـع و البصر يجعل عمليات التعلم أكثر عمقا، يـدعم

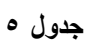

قيم (ر) ودلالتها لمعاملات الارتباط بين مهارات التجهيز السمعي واستراتيجيات الترميز لدى المبصرين

\begin{tabular}{|c|c|c|c|c|c|c|}
\hline \multicolumn{3}{|c|}{ المكفوفون (YV) } & \multicolumn{3}{|c|}{ المبصرون (דז) } & \multirow[t]{2}{*}{ مهارات التجهيز } \\
\hline التخيل & التنظيم & الروتينية & التخيل & التنظيم & الروتينية & \\
\hline$\because \leqslant 0$ & $" .00$ & $" . .7 .-$ & $\because . r 4$ & $" . r \Lambda$ & $\because 1 \wedge$ & التحليل السمعي \\
\hline$" . . V T$ & $" *$ ".TV & ${ }^{*} \cdot . \varepsilon 1-$ & $" * .74$ & $" * .00$ & $. .1 \leqslant$ & سعة الذاكرة السمعية \\
\hline$" .07$ & $* * 71$ & $\because$ * $\{7-$ & $=.07$ & 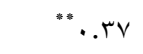 & .1. & التمييز السمعي \\
\hline$" . .7 \mathrm{~V}$ & 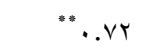 & $\because$ * & $*$ *..$\leqslant 1$ & ". . ro &. $.1 r$ & الإغلاق السمعي \\
\hline$\because \leqslant \wedge$ & $* * .79$ & $. . r T-$ & $* * . . \leq 1$ & $\because . r q$ & ".ro & الوعي الفونولوجي \\
\hline$* . .09$ & $* * .70$ & .ru- & *.r人 & * . . ro & $\because \leqslant r-$ & الشكل والأرضية" \\
\hline$* * .70$ & $* * .00$ & $. .17-$ & $* *$ &. .19 & $\ldots .0-$ & التزابط السمعي \\
\hline$\ldots v$ &. .19 & .11 & $\because r \Lambda$ & $\cdot . r)$ & $. r \Lambda-$ & الفهم السمعي \\
\hline.$r r$ & $\because \leqslant \wedge$ & $. r q-$ & *.r & $* . .07$ &. .19 & ذاكرة الجمل \\
\hline. .79 &.$v 1$ & .. $\varepsilon \cdot-$ & " & $" .07$ & $\because$ *YY- & الدرجة الكلية \\
\hline
\end{tabular}


مهارات التجهيز و اسـتر اتيجيات التر ميـز تـزداد

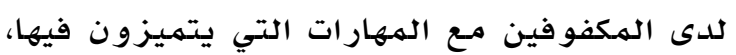

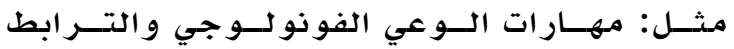

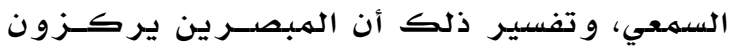

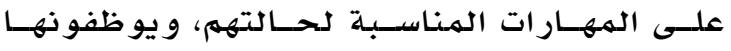
التوظيف المناسب في استر اتيجيات الترميز ، كما

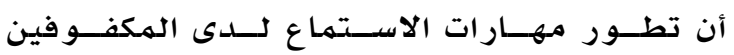
تنعكس إيجابيا على بعض الاستر اتيجيات التـي لا لا

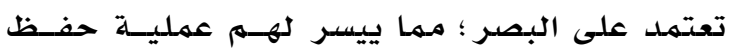
المعلو مات و استدعائها ، و تتفق النتيجــة السـابقة

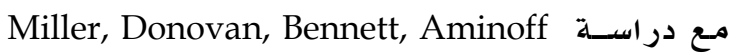
(\& Mayer, 2012)

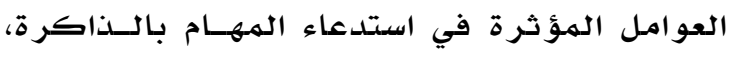

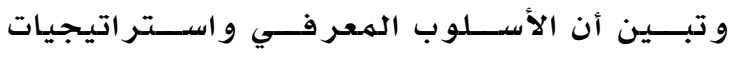

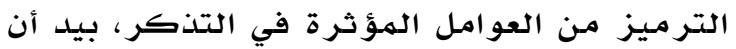

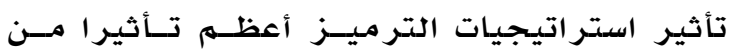

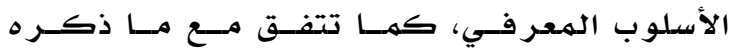
(Kirchhoff \& Buckner, 2006, 263)

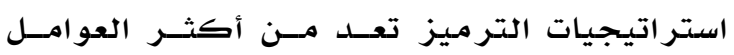
المؤثرة في التذكر ، حيث تبين أن الأفر اد الذين

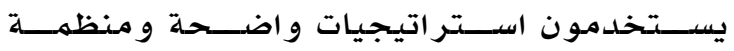
للتذكر تكون ذاكر تهم أفضـل بالهقارنــة بهـن يستخدمون استر اتيجيات سطحية.

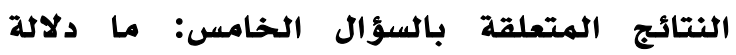
العلاقة بين استراتيجيات الترميز وعمليات التعلم تم استخدام معامل ارتباط بير سون لتعرف دلالة

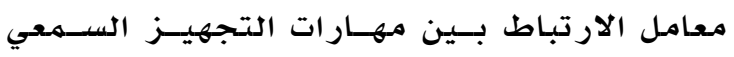

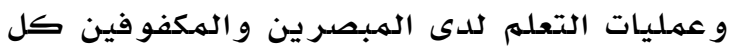
على حدة؛ نظرا لوجـود فـروق بينهـهـا، وجــاءت النتائج و فقا لجدول
النتائج المتعلقة بالسؤال الرابع: ما دلالة العلاقة

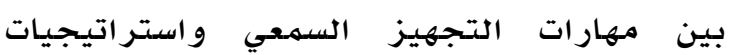

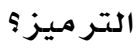
تم استخدام معامل ارتباط بيرسون لتعرف دلادلة معامل الارتباط بين مهارات التجهيز السهعي و عمليات التعلهم لدى المبصر ين و المكفوفين كل

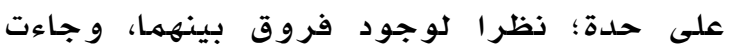
النتائج وفقا لجدول يعرض جلدول ه نتائج معامـلات الارتبـاط، حيـث وهن يتضح وجود علاقة ارتبـاط دالسة وموجبـة بـين غالبية مهارات التجهيـز السـهعي واســـر اتيجيات

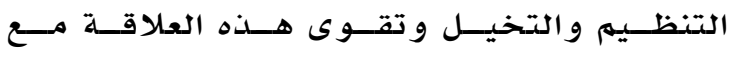

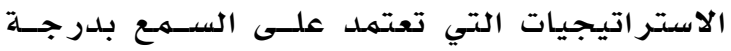

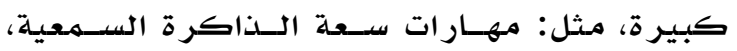

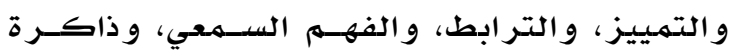

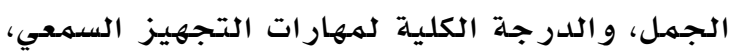
كها لا توجد علاقة أو توجد علاقة سـالبة بـين

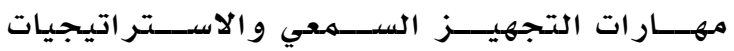

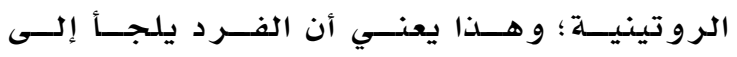

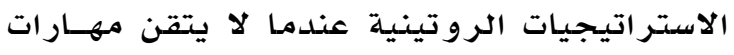

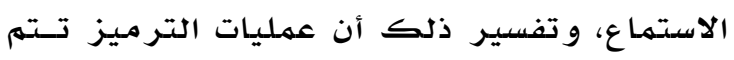

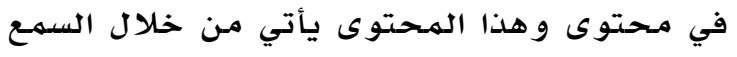

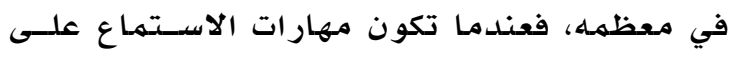
درجة عالية من الكفاءة فإنها تلدعم اسـتر اتيجيات

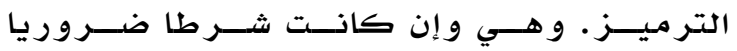
لفاعلية استر اتيجيات الترميز، فإنها غير فان كافية؛

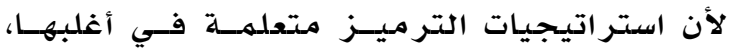

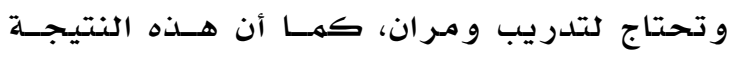
تشير إلى أهمية سلامهة المدخلات لعملية تجهيـز

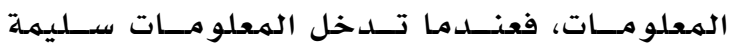

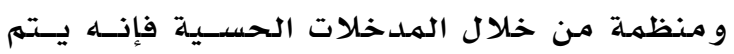
ترميزها بطريقة صحيحهة، كما أن العلاقة بـين

جدول

قيم (ر) ودلالتها لمعاملات الارتباط بين استراتيجيات الترميز وعمليات التعلم جلم

\begin{tabular}{|c|c|c|c|c|c|c|}
\hline \multicolumn{3}{|c|}{ المكفوفون (rv) } & \multicolumn{3}{|c|}{ المبصرون (דا7) } & \multirow[t]{2}{*}{ عمليات التعلم } \\
\hline التخيل & التنظيم & الروتينية & التخيل & التنظيم & الروتينية & \\
\hline אז. & $* * .71$ & $. .00-$ & *. $r V$ & $* r V$ & $\cdot . \wedge-$ & طرق الدراسة \\
\hline$* . \leqslant 1$ & ת & $.17-$ &. .19 & $* * . . \leqslant 1$ & $\cdot .7-$ & العميقة \\
\hline.$r v$ & $* * . . \leq 9$ & $\ldots 1$ & * & דr.". & $\cdots \leqslant-$ & الحفظ \\
\hline.$r V$ & $* * .0$ & $\ldots$ & $* r \Lambda$ & $* * . . \leqslant \leq$ & $\cdots 99-$ & الموسعة \\
\hline
\end{tabular}

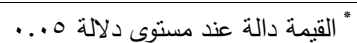

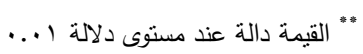


في الذاكرة يعتمدل بلدرجــة كبيـرة علـى قـدرة المتعلهم على تطــوير نظــام لتحليـل المعلومـــات

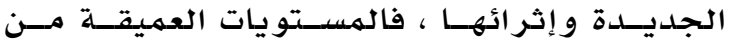
التجهيز تركز على استخلاص المعاني والتحليل المجررد ذي الهعنى، فيؤدي إلى حلدوث آثار أكثر

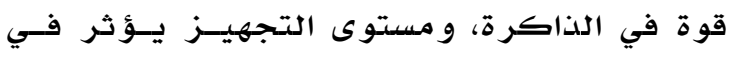
موضوع التذكر سواء أكان كلهمات أو صورا أو أو

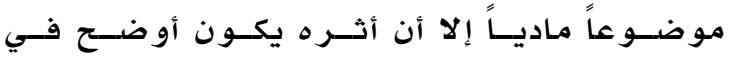
الموضوضو عات اللفظية.

النتائج المتعلقة بالسؤال السادس: ما دلاكلة معامل

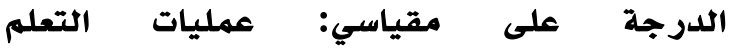
واستر اتيجيات الترميزء

لإِجابة عن هذا السؤال استخدلم الباحسث معامـل الانحدار المتعدد بطريقة (Stepwise) الذي يتـيح

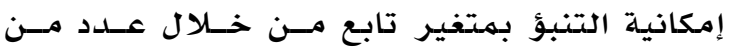

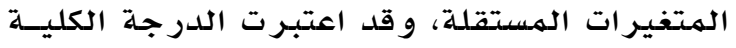

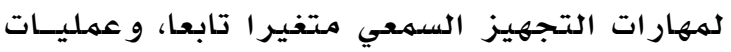
التعلهم و استر اتيجيات الترميز متغيــر ات مســتقلة

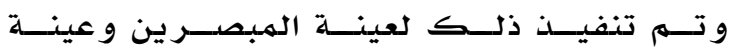
المكفوفين كل على حدة؛ نظـــرا لوجــود فــروق

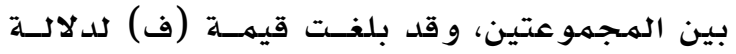

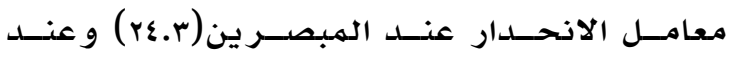

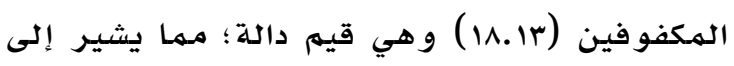
كفاءة نموذج الانحدار بالتنبؤ بمهار ات التجهيـز السمعي من خلال المتغير ات المستقلة . لمهيلة وجدول V التالي يوضح قيه R \& R وقيمـة الثابت

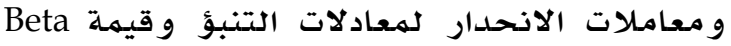
و المتغير ات المنبئة بههارات التجهيز السمعي. الانحدار للتنبؤ بمهارات التجهيز السمعي من

يعر ض جلدو ل 1 نتائج معاملات الارتبـاط، حيـث يتضح وجود علاقة دالة موجبة بين استراتيجيات

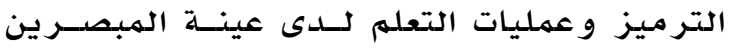
و المكفوفين، و تزداد العلاقة بين عمليـات الـتعلهم الأكثر عمقا و اسـتراتيجيات التنظـيم و والتخيـل

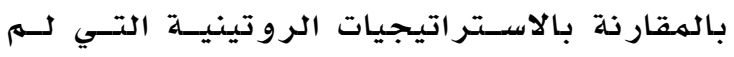

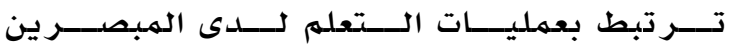

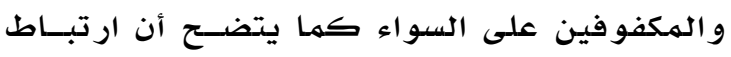

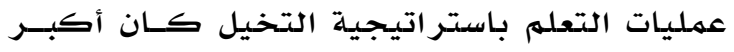
لدى عينـة المبصرين بالمقار نة بعينة المكفـوفين

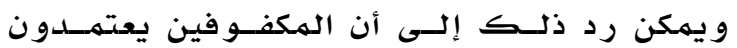
فقط على ترميز المعنى لافتقادهم لحاسـة البصر البـ البر

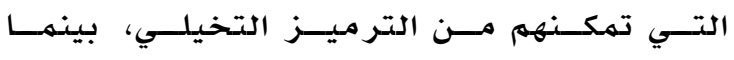
الهبصرون يستخدمون كالا النوعين من الترميز

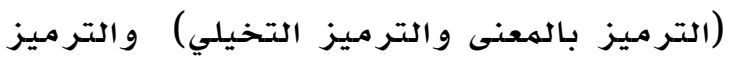
التخيلي يستخدم في كثير مسن عمليسات الـتعلهم وهذا مسا أثــار إليسه ( \&oley, Hughes, Librot \& حيــث أثــاروا إلـــى أن (Paysnick, 2008, 831

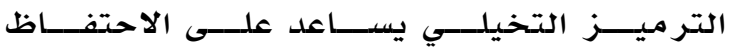

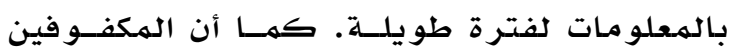
يخز نون المعلو مات في الذاكرة الســمعية فقـط،

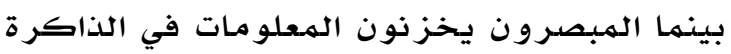

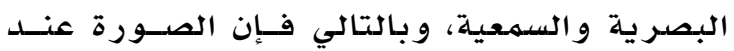
المكفــوفين تكــون أوضــح و أدق و أقــل قابليـــة

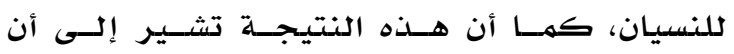
عمليات التعلهم واستر اتيجيات الترميز، كل منهما يدعم الآخر ، فإذا كانت عمليـات الـتعلهم الأعمـق تحتاج إلى جهد كبير و مقصود مـن الطادب، فـإن

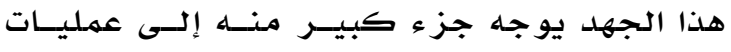

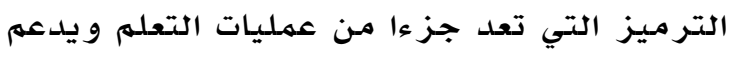
ذلك ما ذكـره ) Bernstein, Beig, Siegenthaler, من أن الاحتفـاظ بالمعلومـات (Grady, 2002, 87 جدول قيمة الثابت و Beta ومعاملات الانحار لمعادلات التنبؤ عند الذكور

\begin{tabular}{|c|c|c|c|c|c|c|c|}
\hline معاملات الانحدار (B) & Beta & 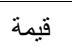 & قيمة R2 & ق قيمة R & قيمة الثابت & المتغيرات المستقلة & المجموعة \\
\hline$* r .01$ & &. .7 & & & & استراتيجية الترميز ( التخيل) & \\
\hline 1.97 & &.$r r$ & $.0 \leqslant$ & $\cdot . \vee \leqslant$ & 9.15 & استراتيجية التزميز ( الروتينية) & مبصرون \\
\hline.$r$. & & $\cdot r_{1}$ & & & & عملية التعلم (طرق الدراسة) & \\
\hline$*$ * . $\leqslant 9$ & & $\because 7$ &. .7 . &..$\vee \wedge$ & T. & استراتيجية التزميز ( التظظيم) & مكفوفون \\
\hline. $.0 \mathrm{~V}$ & &.$r \varepsilon$ & & & & عملية التعلم (العميقة) & \\
\hline
\end{tabular}




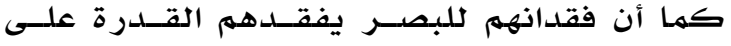

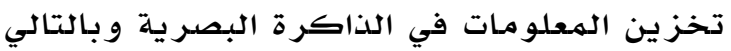

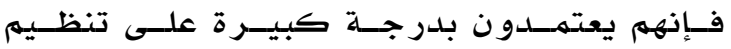
الهعلومات كبديل للاستر اتيجيات التخيلية ووهذا

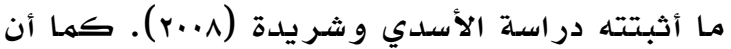
عمليات التعله العميقة تتطلـب التقيـيهم النقـدي

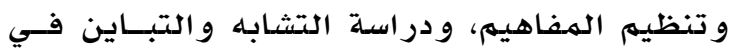
الهمعلومات بهدف معرفة الفروق بينهـا وهــو مــا يصعب على المكفو فين في ظل فقد البصـر ، لكـن عمليـات طـرق الدر اســة تهـتم بـالإجر اءات التــي يتبعها الطالب للاحتفاظ بالمعلوومات كتلخيصها

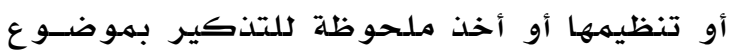
التعلهم و هذا ما يناسب المكفو فين.

وخلاصدة البحث أن مهارات التجهيز السمعي أعلى

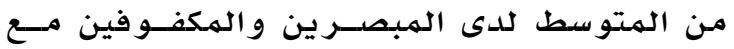
وجود فروق بيـنهم فـي بعـ الههــارات، كهـا

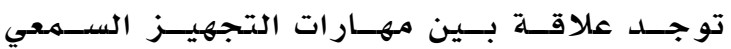
و عمليات التعلهم، ويمكن التنبؤ بههارات التجهيـز

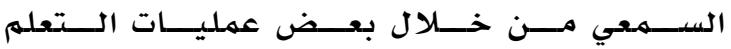

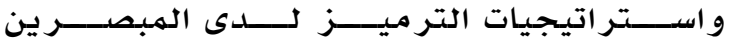

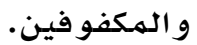

التوصيات

في ضوء مـا توصل إليه البحث من نتـائج يوصـي بما يلي:

ا الاهتمــام بتــدريب الطـلاب علــى مهـارات

التجهيز السهعي من خلال أنشطة تعليمية يتمر تضمينها في المحتوى الدر اسي.

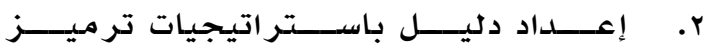
الهعلو مـات و التدريب عليها و توزيعه علـى

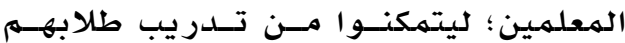
عليها.

r. تعلـيهم الطاسب كيـف يـتعلم مــن خـلال تدريبـه على عمليات الـتعلهم التــي تحتــاج

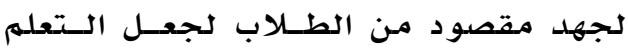
أقوى أثرا و أكثر استدامـة. ع. اكتشــاف طــرق تعلــم الطــلاب و مهــار ات التجهيـز لــديهم و اسـتر اتيـيـيات التر ميـز التي يستخدمونها للعهل على تطوير ها.
يعر ض جدو V Vما يلي: بالنسبة لمجموعة المبصـرين: جـاءت قيمسـة

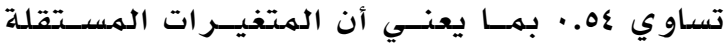

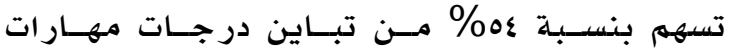

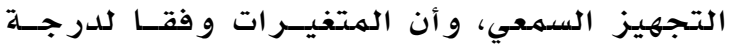
إسهامها في التنبؤ بالمتغير التابع يمكن ترتيبهـا التها و فقا لقيمهة Beta كالتالي(اســتر اتيجية الترميـز

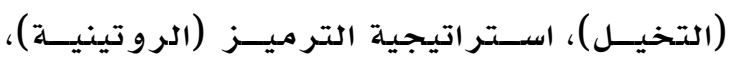

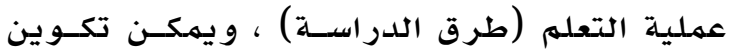
معادلة التنبؤ كالآتي:

درجة مهـارات التجهيـز السـمعي =

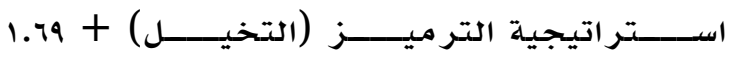

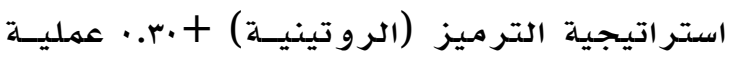
التعلهم (طرق الدراسة).

بالنسبة لمجموعة المكفوفين: جـاءت قيمسة

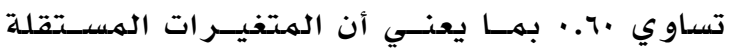

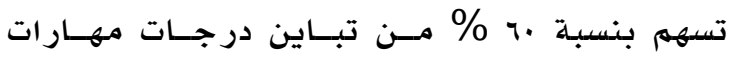

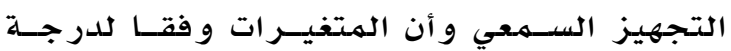
إسهامها في التنبؤ بالمتغير التابع يمكن ترتيبهـا

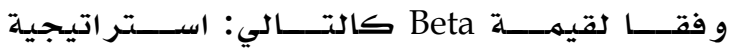

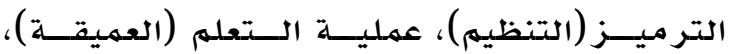
ويمكن تكوين معادلة التنبؤ كالآتي:

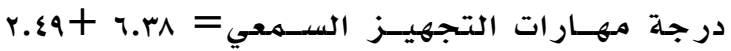

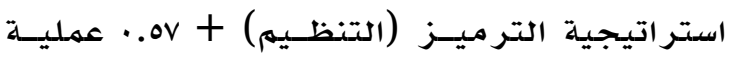
التعلهم (العميقة). و تلدعم نتيجة هذا الفرض نتائج الفروض الثلاثة

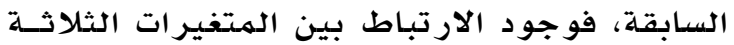
الذي تم تفسيره من قبل فـي الفـروض ضـ الســابقة

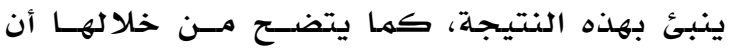

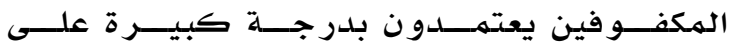

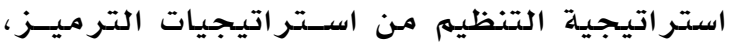

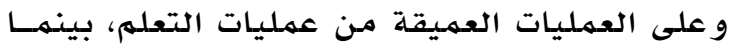

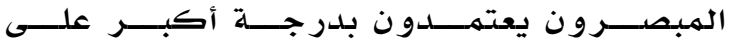
استر اتيجية التخيل والاستر اتيجية الروتينية من

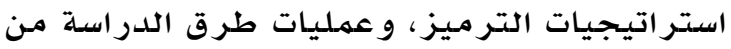

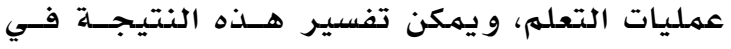
ضوء فقدان البصر لدى المكفوفين، وبالتالي فهم لا يستطيعون تكوين صور تخيلية عن الموضوع، 
و المـــر اهقين. القتـاهرة : مكتبـــة النهضـــة

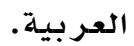

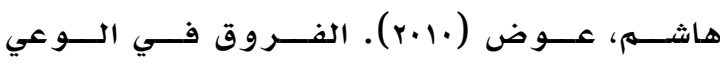

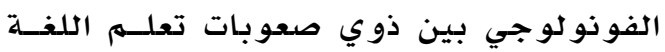

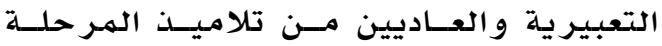

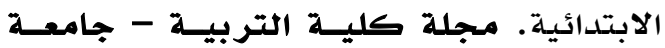

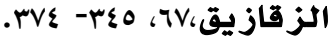

Akpinar, L., S., Popovi, S. \& Kirazci, S. (2012).

Transfer of learning on a spatial memory task between the blind and sighted people. Coll. Antropol. 36 (4), 1211-1217.

Amedi, A., Von Kriegstein, K., Van Atteveldt,

N. M., Beauchamp, M. S., Naumer, M. J.

(2005). Functional imaging of human cross modal identification and object recognition. Experimental Brain Research. $166,559-571$.

Bellis, T. J. (2003). Assessment and management of central auditory processing disorders in the educational setting: from science to practice. San Diego, CA: Singular Publishing Group.

Benjamin, A. S. (2008). Memory is more than just remembering: strategic control of encoding, accessing memory, and making decisions. in Ross, B. H. (Eds). Skill and strategy in memory use. The psychology of learning and motivation. 48, (pp. 175-223). San Diego, CA, US: Elsevier Academic Press.

Bernstein, L., Beig, S., Siegenthaler, A. \& Grady, C. (2002). The effect of encoding strategy on the neural correlates of memory for faces. Neuropsychologia. 40 , 86-98.

Brigitte, R., Frank, R. \& Neville, H. (2001). Auditory memory in congenitally blind adults: a behavioral - electrophysiological investigation. Cognitive Brain Research,11(2),289-303.

Bryan, J., Luszcz, M. \& Pointer, S. (1999). Executive function and processing resources as predictors of adult age differences in the implementation of encoding strategies. Aging, Neuropsychology, and Cognition, 6(4), 273287.

\section{المر اجح}

References

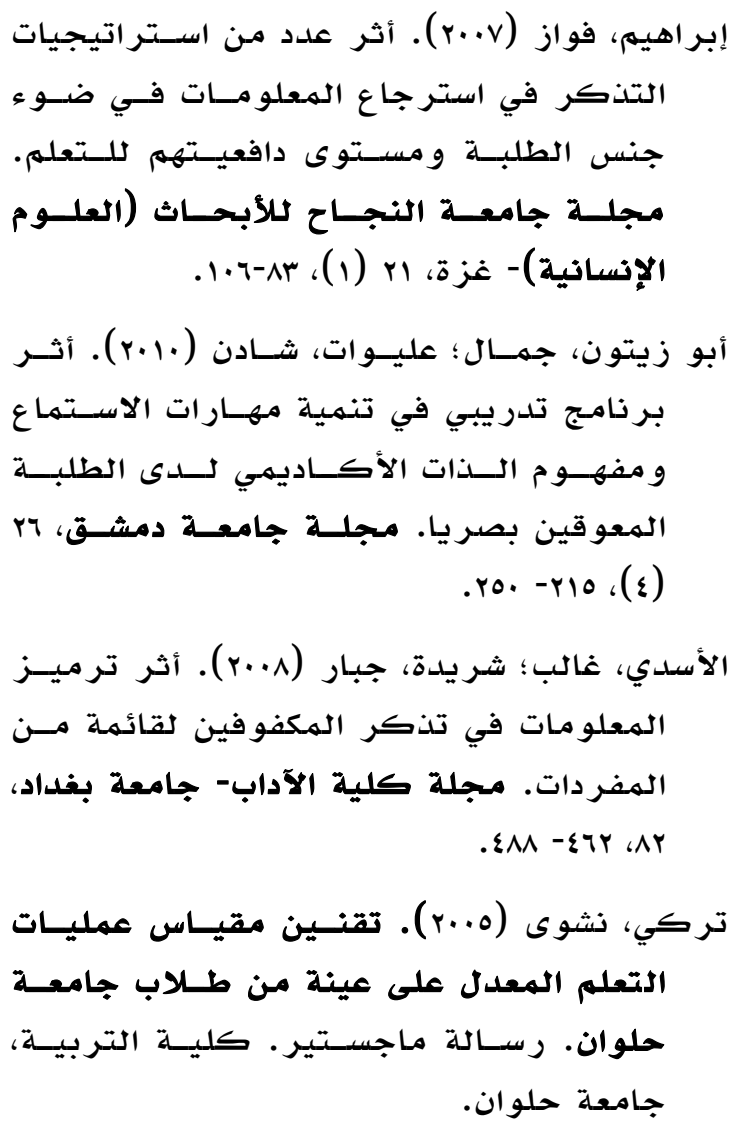


Chen,Q., Zhang, M. \& Zhou, X. (2006). Spatial and nonspatial peripheral auditory processing in congenitally blind people. Neuroreport, 17(13),1449-1452.

Collignon, O., Renier, L., Bruyer, R., Tranduy, D., Veraart, C. ( 2006). Improved selective and divided spatial attention in early blind subjects. Brain Research. 1075, 175-182.

Corriveau, K., Pasquini, E. \& Goswami, U. (2007). Basic auditory processing skills and specific language impairment: A New Look at an Old Hypothesis. Journal of Speech, Language, and Hearing Research, 50, 647-666.

Edmonds, C. J. \& Pring, L. (2006). Generating inferences from written and spoken language: a comparison of children with visual impairment and children with sight. British Journal of Developmental Psychology, 24I(2), p337-351.

Edwards .K. M. (2006). The test of auditory processing skills, third edition (taps-3): validity analyses and reconceptualization based on the cattell-horn-carroll model of cognitive abilities. Doctoral Dissertation, Auburn University.

Foley, M. Hughes, K., Librot, H. \& Paysnick, A. (2008). Imagery encoding effects on memory in the drm paradigm: a test of competing predictions. Applied Cognitive Psychology. 23(6) 828-848.

Freuen, M.T. (2008). Different encoding strategies affect retrieval of information in collaborative groups. Master Dissertation of Science in Applied Psychology, Montana state university, Bozeman: Montana.

Gougoux, F., Zatorre, R.J., Lassonde, M., Voss, P. \& Lepore, F. (2005). A functional neuro imaging study of sound localization: visual cortex activity predicts performance in early-blind individuals. PLoS Biol. 3(2), 27- 33 .

Hotting, K. , Roder, B. (2009). Auditory and auditory-tactile processing in congenitally blind humans. Hearing Research, 258, 165174.

Kirchhoff1,B.A. \& Buckner, R.L. (2006). Functional-anatomic correlates of individual differences in memory. Neuron, 51, 263-274.
Mayers, J. D.(2003). Introduction to psychology. Wadsworth: Belmont.

Miller, M., Donovan, C., Bennett, C., Aminoff, E. \& Mayer, R. (2012). Individual differences in cognitive style and strategy predict similarities in the patterns of brain activity between individuals. NeuroImage. 59(1), 83-93

Offir, B. ,Lev, Y. \& Bezalel, R. (2008).Surface and deep learning processes in distance education: synchronous versus asynchronous systems. Computers \& Education, 51, 1172-1183.

Ormson, K.D. (1995). A study of the performance on auditory processing. tests and conner's rating scale as discriminates of children having attention deficit-hyperactive disorder. doctoral dissertation, The Graduate Faculty of Texas Tech University.

Pan, W. \& Hawryszkiewycz, I. (2004). A method of defining learning processes. In R. Atkinson, C. McBeath, D. Jonas-Dwyer \& R. Phillips (Eds). Beyond the comfort zone: proceedings of the 21st Ascilite Conference (pp. 734-742). Perth, 5-8 December

Phillips, R. A., McNaught, C., \& Kennedy, G. (2010). Towards a generalized conceptual framework for learning: the learning environment, learning processes and learning outcomes (lepo) framework. In J. Herrington \& W. Hunter (Eds.), EDMEDIA 2010 (pp. 2495-2504). Toronto, Canada, Association for the Advancement of Computers in Education.

Robinson, J. P., Shaver, P. R., Wrightsman, L. S. (1991). Measures of personality and social psychological attitudes. San Diego, CA: Academic Press, Inc.

Schmeck, R. R. (1982). Inventory of learning process. in student learning style and brain behavior. Reston: National Association of Secondary School Principals

Schmeck, R. R. (1983). Learning styles of college students. In R. Dillon \& R. Schmeck (Eds.). Individual differences in cognition (pp. 233-279). New York: Academic Press .

Schow, R., Seikel, J. Brockett , J. \& Whitaker, M. (2007). Multiple auditory processing assessment (MAPA). Idaho State University. 
Shepherd, I. (2001). Providing learning support for blind and visually impaired students undertaking fieldwork and related activities. Geography Discipline Network, Gloucestershire, UK

Snell, N.M. (1992). The relationship between academic self-efficacy and the deep processing scale of the inventory of learning processes. Master Dissertation, The Graduate School of the Ohio State University.

Stevens, A. A., Weaver, K. E. (2009). Functional characteristics of auditory cortex in the blind. Behavioral Brain Research. 196, 134-138.

Ungar, S., Simpson, A. \& Blades, M. (2004). Strategies for organizing information while learning a map by blind and sighted people. In M. Heller \& S. Ballasteros (Eds.), Touch, Blindness and Neuroscience. Madrid: Universidad Nacional de Educacion a Distancia.

Vaghefi, M., Tehrani, L., Shirazi, T. , Rezaei, M. \& Rahgozar, M.(2013). Phonological processing skills in 6 year old blind and sighted persian speakers. Audiology. 22(1), 50-57. 